\title{
Constraining families of dynamic models using geological, geodetic and strong ground motion data: The Mw 6.5, October 30th, 2016, Norcia earthquake, Italy
}

\author{
Elisa Tinti ${ }^{\mathrm{a}, \mathrm{b}, *}$, Emanuele Casarotti ${ }^{\mathrm{b}}$, Thomas Ulrich $^{\mathrm{c}}$, Taufiq Taufiqurrahman ${ }^{\mathrm{c}}$, Duo $\mathrm{Li}^{\mathrm{c}}$, \\ Alice-Agnes Gabriel ${ }^{c, d}$ \\ a Università La Sapienza, Rome, Italy \\ b Istituto Nazionale di Geofisica e Vulcanologia, Rome, Italy \\ ${ }^{c}$ Department of Earth and Environmental Sciences, Ludwig-Maximilians-Universität München, Munich, Germany \\ d Institute of Geophysics and Planetary Physics, Scripps Institution of Oceanography, University of California, San Diego, CA, USA
}

\section{A R T I C L E I N F O}

\section{Article history:}

Received 1 June 2021

Received in revised form 9 September 2021

Accepted 1 October 2021

Available online 14 October 2021

Editor: R. Bendick

\section{Keywords:}

earthquake source

data-integrated dynamic modeling

frictional heterogeneity

dynamic rupture

high-performance computing

\begin{abstract}
A B S T R A C T
The 2016 Central Italy earthquake sequence is characterized by remarkable rupture complexity, including highly heterogeneous slip across multiple faults in an extensional tectonic regime. The dense coverage and high quality of geodetic and seismic data allow us to image intriguing details of the rupture kinematics of the largest earthquake of the sequence, the $\mathrm{M}_{w} 6.5$ October 30th, 2016 Norcia earthquake, such as an energetically weak nucleation phase. Several kinematic models suggest multiple fault planes rupturing simultaneously, however, the mechanical viability of such models is not guaranteed.

Using 3D dynamic rupture and seismic wave propagation simulations accounting for two fault planes, we constrain "families" of spontaneous dynamic models informed by a high-resolution kinematic rupture model of the earthquake. These families differ in their parameterization of initial heterogeneous shear stress and strength in the framework of linear slip weakening friction.

First, we dynamically validate the kinematically inferred two-fault geometry and rake inferences with models based on only depth-dependent stress and constant friction coefficients. Then, more complex models with spatially heterogeneous dynamic parameters allow us to retrieve slip distributions similar to the target kinematic model and yield good agreement with seismic and geodetic observations. We discuss the consistency of the assumed constant or heterogeneous static and dynamic friction coefficients with mechanical properties of rocks at 3-10 km depth characterizing the Italian Central Apennines and their local geological and lithological implications. We suggest that suites of well-fitting dynamic rupture models belonging to the same family generally exist and can be derived by exploiting the trade-offs between dynamic parameters. Our approach will be applicable to validate the viability of kinematic models and classify spontaneous dynamic rupture scenarios that match seismic and geodetic observations as well as geological constraints.
\end{abstract}

(C) 2021 The Authors. Published by Elsevier B.V. This is an open access article under the CC BY-NC-ND license (http://creativecommons.org/licenses/by-nc-nd/4.0/).

\section{Introduction}

Kinematic modeling is a standard tool to image the slip behavior of faults during earthquakes of moderate-to-large magnitude. Kinematic models (Haskell, 1964) prescribe the spatio-temporal evolution of slip on a fault as a result of solving data-driven inverse problems. Automated procedures deriving kinematic models within a few hours after significant events are an established part of rapid earthquake response information. Refined kinematic mod-

\footnotetext{
* Corresponding author.

E-mail address: elisa.tinti@uniroma1.it (E. Tinti).
}

els often emerge during the months and years after an event using seismic and geodetic data and more advanced numerical methods to closely fit observations with a large number of free parameters (e.g., Wang et al., 2020). Therefore, most significant earthquakes are characterized by several kinematic models that describe the complexity of the seismic process in terms of slip distribution, activated fault planes, fault geometry, and rupture time evolution. More recently, kinematic modelers aim to take uncertainties into account, using, for example, a Bayesian approach (Ragon et al., 2018, and references therein) to mitigate errors and assumptions in the forward modeling, in the adopted Greens' function (Yagi and Fukahata, 2011), in data coverage, and in data resolution. Despite recent advances, kinematic models are characterized by an 
inherent non-uniqueness of the problem (strong trade-offs among kinematic parameters) in addition to aforementioned significant uncertainties and the often required predefinition of fault geometries (with notable exceptions, e.g., Ragon et al., 2018; Shimizu et al., 2020). However, it is uncommon to analyze whether kinematic models are dynamically consistent, i.e., if it is possible to find a configuration of dynamic parameters that yield the same spontaneous rupture history. The scaling and distribution of dynamic source properties can be evaluated from kinematic source models as a solution of the elastodynamic equation when the rupture history is prescribed a-priori on a fault plane. Distributions of the corresponding dynamic parameters can thus be retrieved without the need to use any constitutive law and to assess if the models would propagate spontaneously (e.g., Tinti et al., 2005; Causse et al., 2014).

Fully dynamic modeling of earthquakes provides a physicsbased understanding of how earthquakes start, propagate, and stop. Earthquake dynamic rupture simulations couple the nonlinear interaction of fault yielding and sliding behavior to seismic wave propagation (Harris et al., 2018). Using modern numerical methods and computing infrastructure allows for realistic 3D dynamic rupture scenarios of complex, multi-fault earthquakes (Ando and Kaneko, 2018; Wollherr et al., 2019). Initial conditions, such as geometry, frictional fault strength, tectonic stress state and regional lithology, control rupture propagation style (e.g., pulse vs. cracklike dynamics and sub-Rayleigh vs. super-shear speeds), stress transfers (dynamic triggering, branching), and earthquake arrest (e.g., Gabriel et al., 2012; Bai and Ampuero, 2017; Lambert et al., 2021; Harris et al., 2018).

Since it is challenging to constrain fault stresses and strengths from direct observation, it is common to prescribe fault normal and shear stress as constant or linearly increasing with depth (e.g., Galvez et al., 2014). While matching strong motion records with dynamic rupture simulations can be formulated as an inverse problem with stress and friction as model parameters (e.g., Gallovič et al., 2019), to date, only simplified dynamic rupture simulations are computationally tractable for dynamic source inversion (e.g., Fukuyama and Mikumo, 1993).

Dynamic models can be affected by parameter trade-offs (Guatteri and Spudich, 2000; Schmedes et al., 2010) and the choice of constitutive law (Dieterich, 1979; Ohnaka et al., 1987). Nevertheless, by reconciling findings from experiments (Di Toro et al., 2011; Collettini et al., 2019) and increasingly dense observations, dynamic models can bridge scales and geophysical disciplines to provide insight into the mechanic viability of competing hypotheses for a specific event (Ulrich et al., 2019; Weng and Yang, 2018) or fault system (Murphy et al., 2018; Harris et al., 2021).

Few dynamic rupture models have been proposed of moderate size normal faulting events (e.g., Gallovič et al., 2019; Aochi and Twardzik, 2020). Surface breaching reverse and normal faulting dynamic models are challenged by free-surface induced normal stress, strength, loss of ground motion symmetry, trapped waves in the hanging wall, and other dynamic and quasi-static effects (e.g., Oglesby et al., 1998; Aochi, 2018; Ma and Beroza, 2008).

In this work we develop a systematic approach to constrain spontaneous dynamic models based on a given kinematic model, allowing us to evaluate its dynamic consistency. Such data-driven physics-based models can complement rapid earthquake response and further the fundamental understanding of complex earthquake rupture processes. Specifically, we design and analyze "families" of complex multi-fault dynamic models, each recovering main kinematic characteristics but varying in terms of their initial dynamic parameters which determine frictional strength and stress drop. We consider the well-recorded $2016 \mathrm{Mw} 6.5$ Norcia (Italy) normal faulting earthquake as a case study (Fig. 1). This event is an example of a normal faulting earthquake with a moderate magnitude

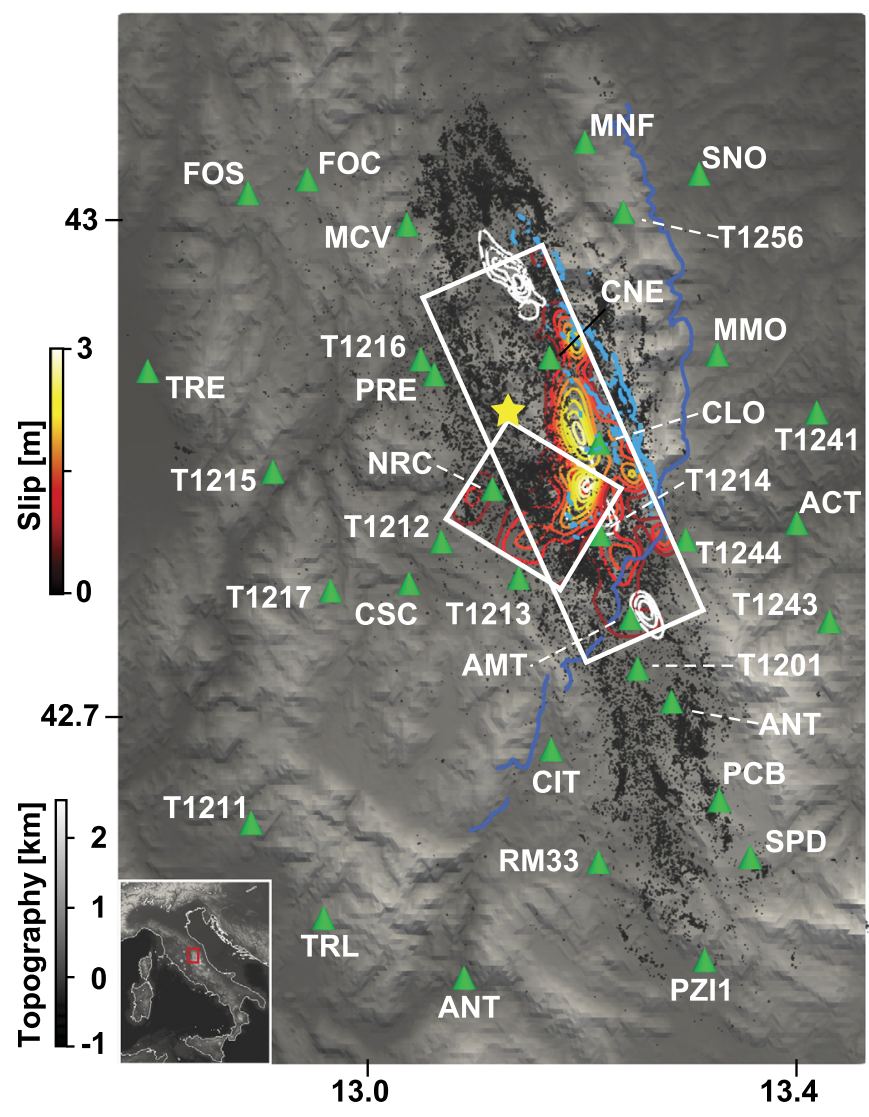

Fig. 1. Map of the study area. Black dots: Amatrice-Visso-Norcia seismic sequence relocated earthquakes from Michele et al. (2020); darker blue lines: fault traces of OAS (Olevano-Antrodoco-Sibillini) thrust fronts; light blue lines: observed surface offsets. Green triangles denote the strong motion stations. Yellow star shows the epicenter of the 2016 Norcia event adopted in this study. White contours are the slip distribution for Visso and Amatrice events, from Tinti et al. (2016); Chiaraluce et al. (2017). The slip distribution of the Norcia event inferred by Scognamiglio et al. (2018) - model S18 - is shown by colored contours. Important characteristics of S18 are the weak nucleation, the main slip patches occurring updip from the nucleation on the two differently oriented faults (white boxes) and the rupture beyond the fault intersection. (For interpretation of the colors in the figure(s), the reader is referred to the web version of this article.)

involving a complex set of intersecting faults. Several models proposed for this event (Chiaraluce et al., 2017; Cheloni et al., 2017; Pizzi et al., 2017; Scognamiglio et al., 2018; Walters et al., 2018; Bonini et al., 2019) generally agree on the location of the main slip release. However, most recent models require two or more connected faults to match all observations available from diverse dataset. The inferred multi-fault geometries are not conflicting; a consensus (Scognamiglio et al., 2018; Michele et al., 2020; Bonini et al., 2019; Walters et al., 2018) is emerging for a multiple-fault model composed of a main normal fault parallel to the Apennines backbone, confined to the southeast by an oblique fault, unfavorably oriented with respect to the current tectonic regime (Mariucci and Montone, 2020). The proposed composite models suggest that these fault planes slipped simultaneously, posing questions about the dynamic plausibility of co-seismic fault interaction.

Here, we focus on the complex kinematic model proposed by Scognamiglio et al. (2018), "S18" hereinafter.

In particular, for each family, we conduct dynamic rupture scenarios of the Norcia earthquake yielding the same kinematic features as the target "S18" model. We validate them with seismic and geodetic observations, overall slip distribution, rake direction, and moment magnitude. We derive a parametrization leading to friction coefficients (static and dynamic) consistent with the mechanical properties of rocks in the Italian Central Apennines. Our 
approach helps to overcome the difficulties in assigning initial modeling conditions for dynamic rupture models in absolute terms and to discuss the lithological meaning of the derived friction parameters.

\section{The $M_{w} 6.5$ October 30th 2016 Norcia earthquake}

The Amatrice-Visso-Norcia (AVN) seismic sequence (Chiaraluce et al., 2017; Michele et al., 2020; Scognamiglio et al., 2018) started on August 24th, 2016, with the Mw 6.0 Amatrice earthquake (Tinti et al., 2016). The largest event, which occurred on October 30th, struck the region close to Norcia village with magnitude $M_{w} 6.5$ and was preceded only four days earlier, on October 26th, by the Mw 5.9 Visso earthquake (Fig. 1). For the Mw 6.0 Amatrice event, simplified dynamic rupture inferences from strong ground motion data (Gallovič et al., 2019; Aochi and Twardzik, 2020) reveal complex dynamics (e.g., two asperities and a slow nucleation phase) and imply that rupture arrested south of the secondary fault activated during the Norcia earthquake.

Similarly, the Norcia earthquake exhibited a large degree of complexity. Our starting point here is the kinematic model "S18" that involves, in addition to the main normal fault parallel to the Monte Vettore-Monte Bove fault systems, a second fault. This secondary fault is ascribed to the inherited Olevano-AntrodocoSibillini Thrust and dislocates as a NNE trending normal fault with a significant strike-slip component (Fig. 1). The "S18" model is obtained from jointly inverting strong motion and GPS data, and is validated using InSAR data (Scognamiglio et al., 2018) and relocated aftershocks (Michele et al., 2020).

The main kinematic characteristics of the "S18" model (Fig. 1) are the following: i) both faults dislocate almost simultaneously, reaching a maximum slip of $3 \mathrm{~m}$; ii) the location of the highslip patches is about $5 \mathrm{~km}$ shallower than the hypocenter while less than $20 \mathrm{~cm}$ of slip is inferred in the nucleation region; iii) the secondary fault is characterized by a predominantly left-lateral strike-slip mechanism within its largest slip patch, but also features local rake variations; iv) the southern part of the main fault, located behind the secondary fault and activated during the first event of the AVN sequence (the Mw 6.0 Amatrice earthquake), is partially reactivated during the Norcia event, with a locally significant amount of slip $(\approx 1 \mathrm{~m})$.

\section{Model setup}

We use the open-source software package SeisSol (www.seissol. org) to model spontaneous dynamic earthquake rupture across intersecting faults and seismic wave propagation with high-order accuracy in space and time (Fig. 2, for details see Appendix A).

Modeling complex fault interaction during dynamic rupture propagation is challenging, specifically across fault junctions and interpenetrating fault surfaces (e.g., Douilly et al., 2020). SeisSol, which is based on the Arbitrary high-order Derivatives Discontinuous Galerkin method (Dumbser and Käser, 2006), naturally allows for discontinuities and fault branching geometries (Pelties et al., 2014).

\subsection{Constitutive law}

We adopt a simple constitutive relationship (Fig. 3) to focus on the effects of heterogeneities in fault strength and stress. The linear slip-weakening (LSW) friction law (Barenblatt, 1959) is a simple and widely used constitutive equation derived from theoretical and numerical models (Andrews, 1976) of shear crack propagation from a macroscopic perspective (Cocco and Tinti, 2008). This constitutive relation is completely characterized by the yield strength $\tau_{y}=\mu_{s} \sigma_{n}$, the dynamic frictional resistance $\tau_{f}=\mu_{d} \sigma_{n}$, and the critical slip distance $D_{c}$, where $\mu_{s}$ and $\mu_{d}$ are the static and dynamic friction coefficients, respectively, and $\sigma_{n}$ is the effective normal stress. The fault begins to rupture when shear stress locally exceeds $\tau_{y}$ and frictional fault strength decreases linearly from a static to a dynamic level over a critical slip distance $D_{c}$. For a slip greater than $D_{c}$, fault strength remains constant equal to $\tau_{f}$ (i.e., no healing). The distribution across the fault plane of the strength excess $\left(\tau_{y}-\tau_{0}\right)$, with the initial shear stress $\tau_{0}$, and the dynamic stress drop $\Delta \sigma=\tau_{0}-\tau_{f}$, influences the ratio of strain energy and fracture energy, and determines local acceleration or deceleration of the rupture front.

Inference of the magnitude and direction of initial stresses is only possible from kinematic slip models in which the temporal rake rotation is well defined (Spudich et al., 1998) otherwise, additional assumptions are required. Here we assume that the initial traction is co-linear with the accumulated slip in kinematic models to ensure physical plausibility (Tinti et al., 2005).

Our spontaneous dynamic rupture model is fully defined in an elastic material by the spatial distributions of initial on-fault shear stress, normal stress, static and dynamic friction coefficients, and $D_{c}$ in addition to the prescribed fault geometry and subsurface structural model. Using the LSW law permits us to potentially relate co-seismic fault-constitutive properties directly to observations, e.g., associating friction coefficients of different rocks with inferred values from laboratory experiments. However, scale-invariances and trade-offs between LSW dynamic parameters are well known (Tinti et al., 2009; Goto and Sawada, 2010): dynamic rupture models based on various dynamic parameter choices can fit seismological data equally well (Guatteri and Spudich, 2000). Dynamic parameters cannot be measured in-situ and often lack physical constraints rendering it difficult to determine them prior to (or after) an earthquake. This yields a wide and highdimensional parameter space which is challenging to fully explore and constrain in a data-driven manner.

Therefore, assumptions have to be made when pre-assigning frictional parameters as well as the absolute amplitudes of initial stresses, which both may be heterogeneously distributed acting across the fault planes (e.g., Ripperger et al., 2007; Causse et al., 2014). This motivates our classification of "families" of dynamic models (section 3.4).

\subsection{Fault geometry}

We use a two-planar-fault geometry (Figs. 1 and 2) derived from Scognamiglio et al. (2018). It consists of a main fault branch $\mathrm{N} 155^{\circ}$ trending along the Apennines (hereinafter F155), and a second fault plane striking $\mathrm{N} 210^{\circ}$ oblique to the Apennines (hereinafter F210). The main fault geometry aligns well with the SAR interferograms, the TDMT moment tensor solution, and the observed surface rupture (Scognamiglio et al., 2018). The secondary fault plane geometry is supported by geodetic observations, the aftershock distribution, the inferred non-double-couple component of the mainshock moment tensor, and by moderate earthquakes of NE-SW trending focal mechanisms in the main fault hanging wall (Michele et al., 2020). The dynamic activation of F210, which is shallowly dipping is a major challenge for this model.

\subsection{Weak dynamic rupture nucleation}

We assume the hypocenter adopted by Scognamiglio et al. (2018) and located at $42.84^{\circ} \mathrm{N}, 13.11^{\circ} \mathrm{E}$ at a depth of $9.52 \mathrm{~km}$ to prescribe the onset of rupture in all our models. The nucleation region is located on fault F155 and intersects the bottom left corner of the F210 fault (see Fig. 1). For the Norcia earthquake, similar to the Amatrice event, only small amounts of slip have been inferred in the hypocentral regions implying a transient, weak nucleation process (Tinti et al., 2016; Gallovič et al., 2019). Weak nucleation 


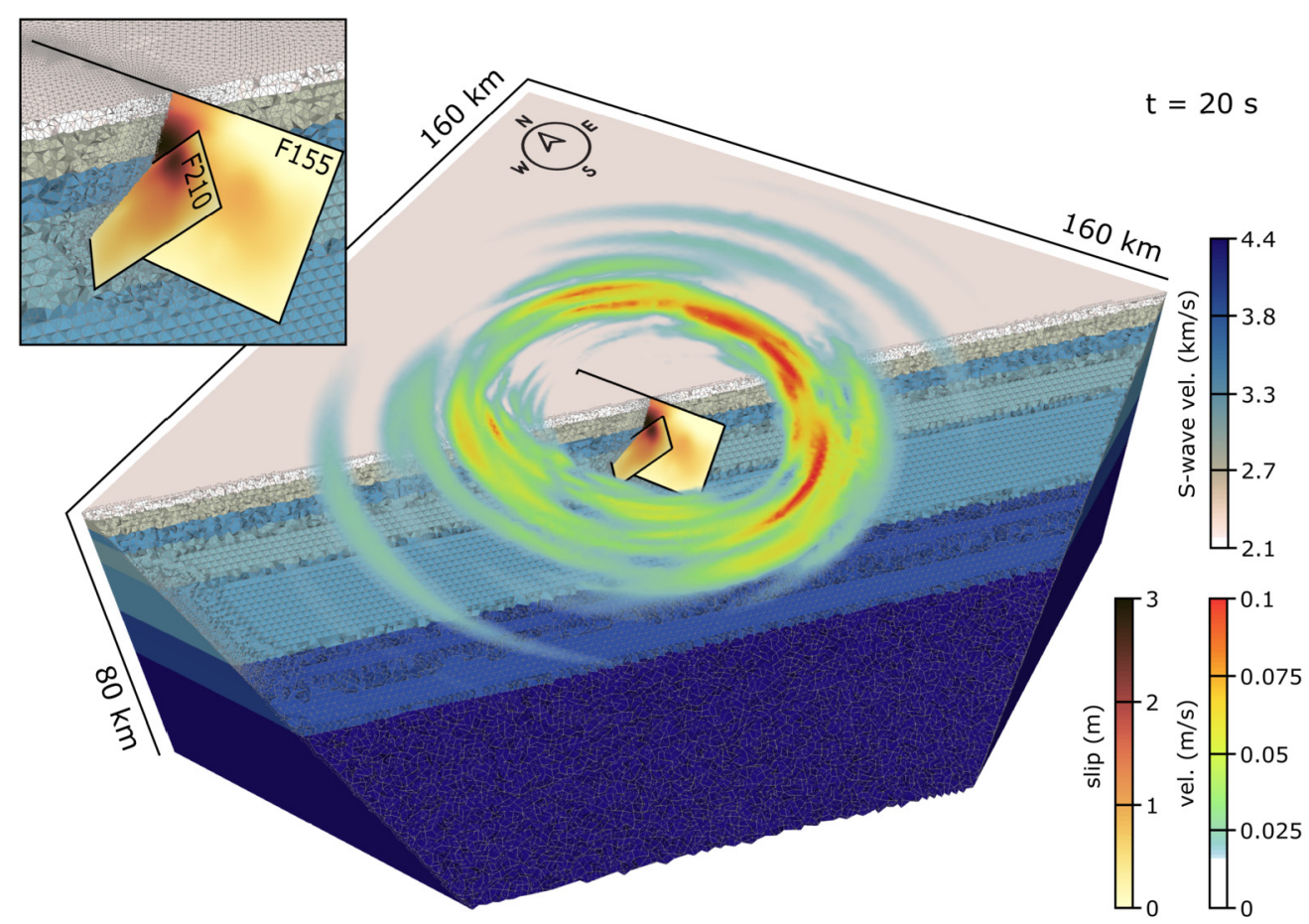

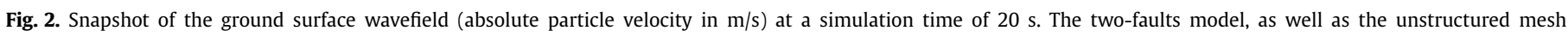

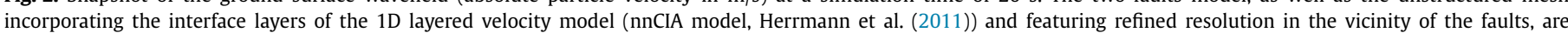

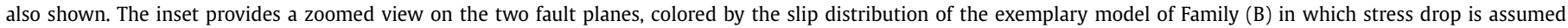

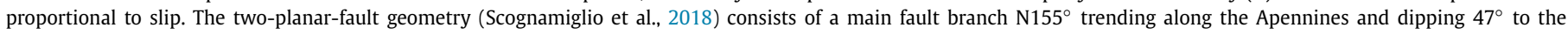

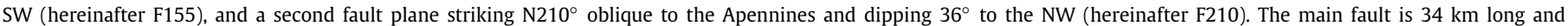

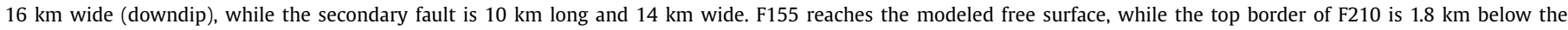
modeled ground surface.

in dynamic rupture models is controlled by spatial heterogeneities and the local closeness to failure of the hypocentral region. We find that locally over-stressing the fault (i.e., assuming the initial stress just above yield stress as, e.g. Palgunadi et al., 2020) tends to create artificially large fault slip in the hypocentral area and unrealistic strong pulses in the synthetic seismograms. Instead, we gradually reduce the yield strength in an elliptical area centered at the hypocenter expanding at time-decreasing speed (Harris et al., 2018) which allows a smooth transition to fully spontaneous dynamic rupture propagation. In conjunction with assuming locally initial shear stresses very close to frictional strength, fault slip in the nucleation area remains limited, matching observations. To dynamically capture the low energy release and small slip during the weak nucleation phase, requires us to carefully balance the sensitive rupture initiation with spontaneous rupture across both activated fault planes. Low energy released in the nucleation zone does not promote spontaneous rupture towards the favorably stressed shallow fault region. Therefore, a large but weak nucleation area is required. For the models proposed, we choose a nucleation initial forcing speed of $2.8 \mathrm{~km} / \mathrm{s}\left(0.7 V_{s}\right)$ and a nucleation radius of 3-6 km, which is of similar size to inferences for the Amatrice event (e.g., Pizzi et al., 2017). The forced nucleation phase contributes in our models during less than 2 seconds with little moment release.

\subsection{Families of initial dynamic parameters}

Dynamic models can be initialized assuming homogeneous or heterogeneous spatial distributions of one or more dynamic parameters governing frictional fault-weakening behavior and initial stresses on the fault plane (e.g., Savran and Olsen, 2020).

To limit the complexity of the dynamic parameterization, it is common to attribute all heterogeneities either only to the initial shear stress distribution or to the yield strength (e.g., Gallovič et al., 2019) while considering the other dynamic parameters constant or homogeneously depth-dependent. In fully elastic dynamic models, the radiated waves are only sensitive to the dynamic stress drop but not to the absolute initial stress.

The main characteristics of the rocks that belong to a specific seismic zone can add lithology-controlled constraints (e.g., Harris et al., 2021). Laboratory experiments on friction coefficients conducted on different types of rocks (Di Toro et al., 2011; Scuderi et al., 2013; De Paola et al., 2015) provide possible ranges of frictional parameters for weak and strong faults (Collettini et al., 2019). Taking laboratory results into account can limit the parameter space to be explored in dynamic models.

Based on these considerations, we identify "families" of dynamic models, consistent with field and laboratory observations but differing in their parameterization of heterogeneous fault stress and strength in the framework of a LSW friction law (Fig. 3):

- Family (Hom) are models based on uniformly depth-dependent stress and strength conditions with constant static $\left(\mu_{s}\right)$ and dynamic $\left(\mu_{d}\right)$ friction coefficients.

- Family (A), the "family of heterogeneous stress", includes all models with constant static and dynamic friction coefficients, linearly depth-dependent initial normal stress but variable initial shear stress $\tau_{0}$.

- Family (B), the "family of heterogeneous strength and stress", includes all models with constant dynamic friction coefficient, depth-dependent initial normal stress but heterogeneous static friction and initial shear stress.

- Family (C), the "family of heterogeneous dynamic friction", includes all models with uniform depth-dependent static friction and initial shear stress but heterogeneous dynamic friction. Family (C) ensures also depth-dependent strength excess. 

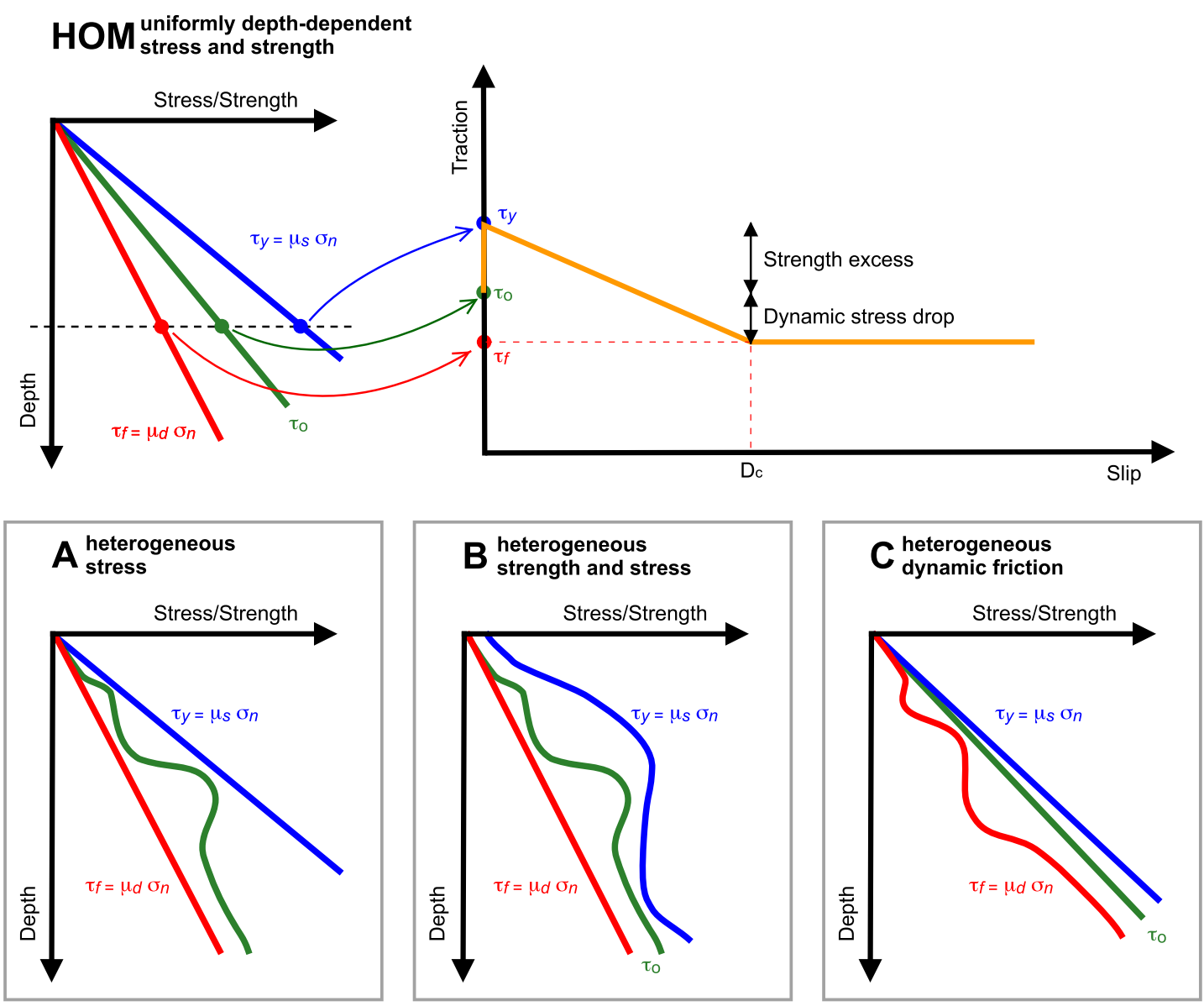

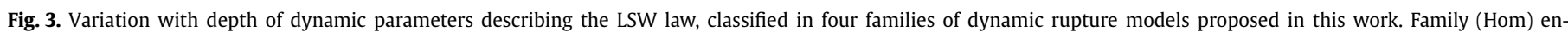

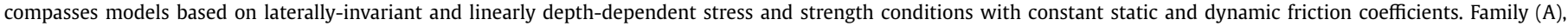

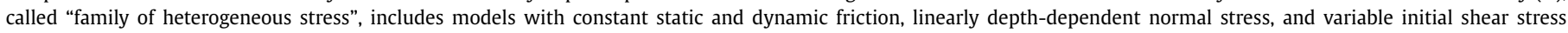

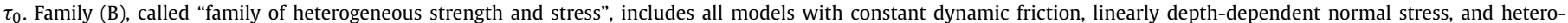

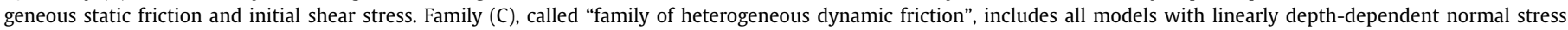
and initial shear stress, constant static friction, and heterogeneous dynamic friction.

A fully heterogeneous Family (D), the "family of heterogeneous strength, stress and friction", is here omitted given the high risk of severe data over-fitting.

We assume that the effective normal stress increases linearly with depth according to a fixed gradient based on an assumed fluid pressure ratio $\lambda$ (defined as the fluid pressure over the lithostatic stress, e.g. Ulrich et al., 2019). The adopted near-hydrostatic fluid pressure ratio $\lambda$ is 0.4 , corresponding to an average gradient around $15 \mathrm{MPa} / \mathrm{km}$. The associated stress and strength parameters $\left(\tau_{0}, \tau_{y}\right.$, and $\left.\tau_{f}\right)$ also vary linearly as a function of depth (see Fig. 3).

Family (A) is our group of simple heterogeneous models: static and dynamic friction coefficients are homogeneous while the initial shear stress is heterogeneous. In this group of models, regions with kinematically constrained low fault slip have very high strength excess and small dynamic stress drop. Such areas, if large enough, do not favor sustained spontaneous rupture since they require more energy than available to overcome the strength excess. This family potentially allows using laboratory-consistent values for both static and dynamic frictions ( $\mu_{d} \approx 0.2$ and $\mu_{s} \approx 0.6$, e.g., Collettini et al., 2019), but is not suited to all kinematic models. Specifically, the "S18" model cannot be reproduced using models belonging to Family (A) due to its low fault slip in the nucleation region: the resulting high strength excess prevents spontaneous rupture propagation.
Moreover, models of this family have a very small strength excess in regions of kinematically inferred high fault slip, such as at the center of the main slip patches (illustrated by the local closeness of $\tau_{0}$ to $\tau_{y}$ in Fig. 3). Thus, Family (A) dynamic models are also prone to a-causal ruptures, that is, failure may happen at many patches instantaneously. Thus, we refrain from further analysis of Family (A) in the remainder of this paper.

Family (B) is a group of heterogeneous models which are frequently proposed for dynamic source inversions (Gallovič et al., 2019). Heterogeneities are attributed to the initial shear stress and yield strength, assuming a constant dynamic friction value. The heterogeneity of stress drop is then completely associated with the initial shear stress. Stress drop corresponding to a prescribed distribution of slip can be retrieved in different ways: for example, by relating stress drop and slip in the wavenumber domain (originally proposed by Andrews (1980) and updated by Ripperger et al. (2007)) or by solving the elastodynamic equation using the entire slip-time history at each point of the fault (e.g., Tinti et al., 2005; Causse et al., 2014).

In this work, we explore two simple approaches. First, we estimate stress drop by assuming direct proportionality with fault slip. In the second approach, we infer the stress drop distribution from the stress change, by imposing the "S18" slip distribution everywhere on the fault (using an arbitrary smooth-step slip-rate function during $1 \mathrm{~s}$ ), and measuring the final shear stress distribu- 
tion (simplifying the approach of Tinti et al., 2005; Causse et al., 2014).

We constrain Family (B)'s yield strength, by assuming a strength excess radially increasing from the hypocenter, with a minimum value of $0.1 \mathrm{MPa}$ at the hypocenter. In addition to the smooth nucleation procedure (Sec. 3.3), this parametrization facilitates nucleation and yields realistic rupture growth.

Family (C) includes models with constant static friction, linearly depth-dependent initial shear stress, and heterogeneous dynamic friction. The resulting yield strength $\tau_{y}$ is only depth-dependent because the effective normal stress is depth-dependent. Heterogeneities in the dynamic friction coefficient stem from the target stress drop distribution, which is retrieved following two different procedures, as in Family (B). While Family (B) has variable $\mu_{s}$ and constant $\mu_{d}$, Family (C) has variable $\mu_{d}$ and constant $\mu_{s}$.

We adopt friction values typical of many lithologies (i.e. 0.5-0.6 for $\mu_{s}$ and 0.1-0.2 for $\mu_{d}$, Collettini et al., 2019) for the constant friction in Family (B) and (C). In contrast, variable $\mu_{s}$ and $\mu_{d}$ are obtained respectively from the assumed heterogeneous stress drop, derived from the "S18" fault slip. We further validate the dynamic models belonging to these two families by assuring that the variable friction values are compatible with the expected rocks in the modeled region and their depths. Introducing Family (C), which is often disregarded among kinematically constrained dynamic models, is motivated by the fact that most rocks favoring the occurrence of seismic events may share similar $\mu_{s}$ around 0.50.6 (Byerlee, 1978).

\section{Results}

The complex spatio-temporal evolution of the AVN sequence, and in particular the distribution and location of the main slip patches of the three main events may suggest strongly heterogeneous initial stress and/or frictional strength and weakening conditions. We first analyze simple models of Family (Hom), based on homogeneous friction, only depth-dependent stress assumptions, to understand which overall conditions favor a spontaneous multi-fault rupture across the assumed fault geometry. Next, we introduce more realistic heterogeneous dynamic models of Family (B) and (C).

\subsection{Homogeneous initial conditions}

Fig. 4 (top panels) shows the on-fault distribution of the most important initial conditions and resulting dynamic parameters for three illustrative dynamic scenarios of Family (Hom). We assume constant static and dynamic friction coefficients of 0.6 and 0.2 , respectively. Furthermore, we set the initial shear stress $\tau_{0}$ as $65 \%$ of the yield strength $\tau_{y}$, which allows dynamic rupture to spontaneously propagate while limiting rupture speed to sub-Rayleigh velocities for most of the fault area. For simplicity, we use on each fault plane a constant shear stress orientation, informed by the average faulting mechanism in the "S18" model: pure normal faulting for the F155 $\left(-90^{\circ}\right)$ and almost pure left-lateral strike faulting $\left(-10^{\circ}\right)$ for the F210 fault.

The magnitude of the initial shear stress $\tau_{0}$ varies on the two fault planes only as a function of depth (Fig. 4) following the normal stress gradient. Fig. 4 (second row) shows the depth-variations of $\tau_{y}, \tau_{0}$ and $\tau_{f}$ as cross-sections. Small offsets are the result of the layered density profile. The nucleation is imposed inside a sphere of radius $3 \mathrm{~km}$. Fixing all other parameters, we here explore how dynamic rupture viability on the main and secondary fault is depending on the choice of $D_{c}$. We confirm that smaller $D_{c}$, i.e. smaller fracture energy with other dynamic parameters kept unchanged, favors dynamic rupture propagation while larger $D_{c}$ inhibits it. We also find that fault interaction (branching, dynamic triggering, shadowing, and co-seismic static slip effects, e.g. Kyriakopoulos et al., 2019) is highly sensitive to choices of $D_{c}$.

For the assumed initial conditions and fault geometries, we find that values of $D_{c} \approx 1-2 \mathrm{~m}$ on the F155 main fault allow rupture propagation at sub-Rayleigh velocity $(<3 \mathrm{~km} / \mathrm{s})$ across most of the slipping area. However, due to the linear depth-dependence of the initial stress, the rupture velocity tends to reach super-shear speeds at shallow depths (e.g., Tang et al., 2021). At the same time, lower values of $D_{c}$ on F210 $(<0.8 \mathrm{~m})$, are needed to allow dynamic rupture propagation there.

In Fig. 4 (top row) we show three $D_{c}$ combinations to illustrate the model sensitivity to this parameter. In the bottom panel, we compare snapshots of slip distributions after a rupture time of $6.75 \mathrm{~s}$ for these three models. Their elliptical slip distributions (generated by crack-like dynamics, e.g., Gabriel et al., 2012) are aided by LSW friction and homogeneous initial conditions. These models are characterized by high slip ( $>10 \mathrm{~m}$ ) in the hypocentral region and by magnitudes much larger than $M_{w} 6.5$ (between $M_{w} 7.14$ and $M_{w} 7.35$, see the right-most panel in the second row of Fig. 4).

Assuming $D_{c}=1.2 \mathrm{~m}$ and $D_{c}=1.0 \mathrm{~m}$ for F155 and F210, respectively, rupture is not simultaneously propagating along both faults (see snapshot at $t=6.75 \mathrm{~s}$ in panel a) but breaking only the main fault including the area beyond the fault intersection. At a later simulation time ( $>8 \mathrm{~s}$, not shown in the figure) slip is observed also on F210, which is dynamically initiated by reflections at the free surface and at the interfaces of the layered velocity structure. Assuming $D_{c}=1.2 \mathrm{~m}$ and $D_{c}=0.8 \mathrm{~m}$ (panel b) for F155 and F210, respectively, both faults rupture simultaneously. Interestingly, rupture of F155 behind the intersection is initially prevented due to stress shadowing (e.g., Bhat et al., 2007) from the F210 rupture. Finally, assuming $D_{c}=1.8 \mathrm{~m}$ and $D_{c}=0.8 \mathrm{~m}$ for $\mathrm{F} 155$ and F210 (panel c), respectively, shows again simultaneous rupture on both fault planes. Initially, this model features a slower rupture (the rupture front is closer to the hypocenter at $6.75 \mathrm{~s}$ compared with panel $b$ ). Again, rupture propagation beyond the intersection with F210 is hindered. In the models of panels b and c, the rupture is able to propagate beyond the fault intersection with a delay of several seconds, which makes this secondary propagation more akin to a triggered event rather than a slow rupture.

We find that $D_{c}^{F 210}>0.8 m$ prevents dynamic rupture on F210 (for the here assumed stress conditions and nucleation). As an additional constraint, if dynamic rupture on F210 is prevented, F155 can host spontaneous rupture propagation only if $D_{c}^{F 155}<1.2 \mathrm{~m}$. Therefore, high values of $D_{c}$ on the main fault need to be combined with low values of $D_{c}$ on the secondary fault to allow rupture across both fault planes in the dynamic rupture Family (Hom). Assuming pure normal faulting for both faults results in even less favorable conditions for sustained rupture on F210 and very small $D_{c}$ values are required to dislocate both fault planes (models not presented).

The presented models have the same ratio of initial shear stress $\tau_{0}$ over yield strength $\tau_{y}$. Exploring alternative ratios, as well as different ratios on each fault, will likely influence the critical $D_{c}$ values that allow rupture on one or both faults. A full analysis of this variability, as well as variations in nucleation, is possible but beyond the scope of this study.

Fracture energy, defined as $G_{c}=1 / 2\left(\tau_{y}-\tau_{f}\right) D_{c}$ (e.g., Palmer and Rice, 1973), increases with depth in Family (Hom) and varies linearly with $D_{c}$ between models. The average fracture energy in the examples is $\approx 20.6-29.3 \mathrm{MJ} / \mathrm{m}^{2}$ (see right-most panel in the second row of Fig. 4) which is comparable to estimates inferred for past earthquakes of similar magnitude (Viesca and Garagash, 2015). We note that fracture energy on both fault planes is roughly equivalent for both models in panels $a$ and $b$, despite their distinct rupture dynamics (Guatteri and Spudich, 2000). 

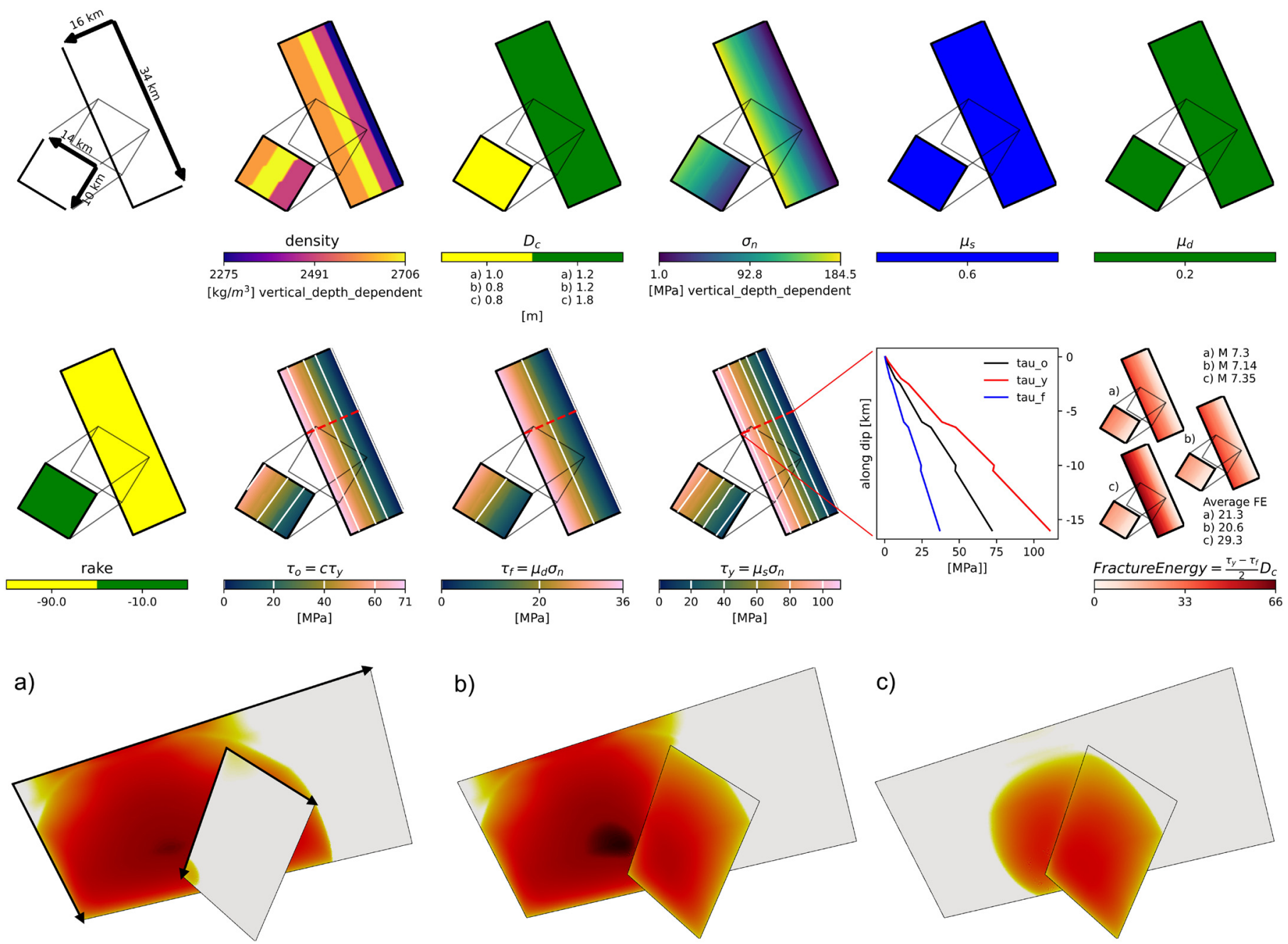

Slip $(6.75 \mathrm{~s})$

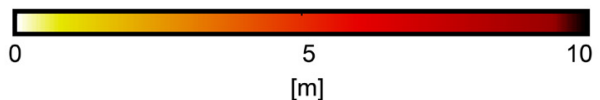

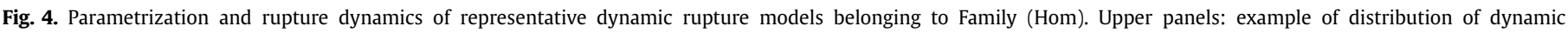

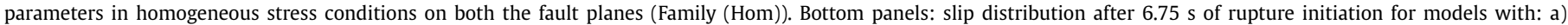

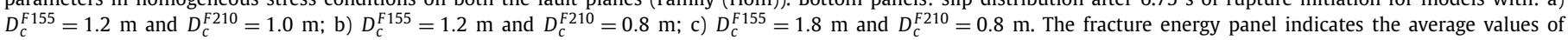
fracture energy $E_{g}$ and the moment magnitude $M_{w}$ values after the ruptures termination.

Using simple forward dynamic rupture models of Family (Hom) we show that a multi-fault rupture is plausible. Assuming homogeneous, depth-dependent stress and strength conditions can lead to left-lateral strike-slip faulting on the secondary fault (F210) and normal faulting on the main fault (F155). The synthetic waveforms resulting from dynamic rupture models of Family (Hom) are very different from observations. While we do not systematically explore the parameter space of all possible constant values of $\mu_{s}$, $\mu_{d}$, and $D_{c}$, this nevertheless suggests that the real dynamic initial conditions may have been strongly heterogeneous. We next explore the space of the dynamic parameters with heterogeneous stress and/or strength conditions to propose dynamic models that reproduce the main features of the "S18" model.

\subsection{Heterogeneous initial conditions}

We here investigate models of Families (B) and (C) having heterogeneous stress and strength as defined in Section 3.4. We identify plausible rupture models, representative of their respective family. These models are consistent with the "S18" inverted kinematic characteristics and with observations (Appendix B). We do not claim that these models are the dynamic models that best fit the data, due to trade-offs between the dynamic parameters. Instead, we suggest that suites of well-fitting models belonging to the same family exist and can be derived by exploiting the tradeoffs between their dynamic parameters. We first show models that assume a direct proportionality between fault slip and stress drop (Sec. 4.2.1) and, secondly, models in which the stress drop is kinematically inferred as the stress change associated with the "S18" model (Sec. 4.2.2).

\subsubsection{Stress drop proportional to fault slip}

In Fig. 5 we show the dynamic parameter distributions of two representative models belonging to Family (B) and (C), respectively. Family (B) (panel a) has heterogeneous distributions of initial shear stress and yield strength. The latter is parameterized as a heterogeneous distribution of $\mu_{s}$ in the range of $[0.2,0.7]$ while $\mu_{d}$ is kept constant at 0.2 . Family (C) (panel b) has heterogeneous dis- 
a)
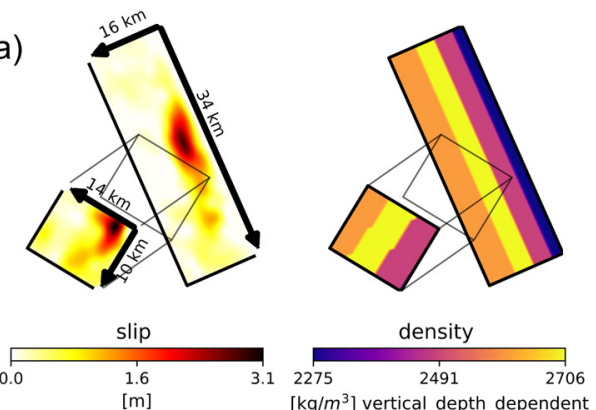

$\left[\mathrm{kg} / \mathrm{m}^{3}\right]$ vertical_depth_dependent
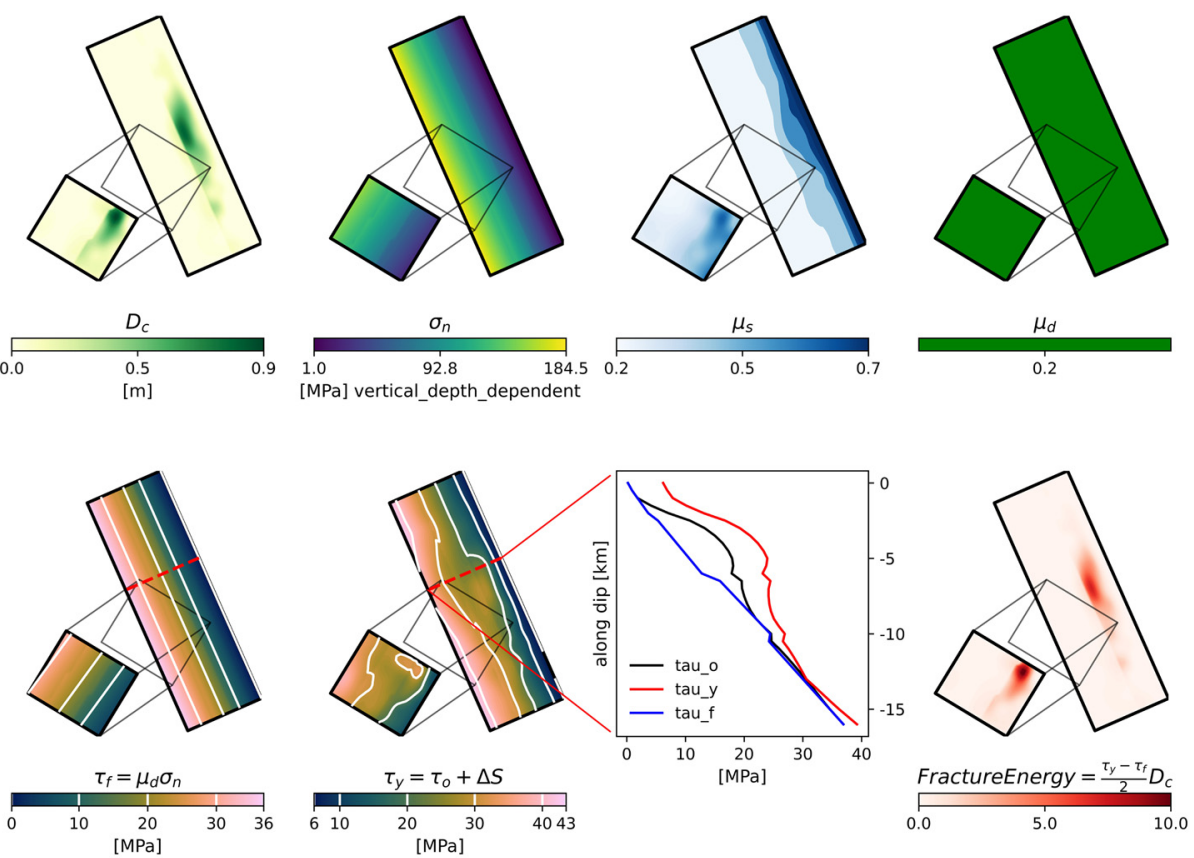

b)
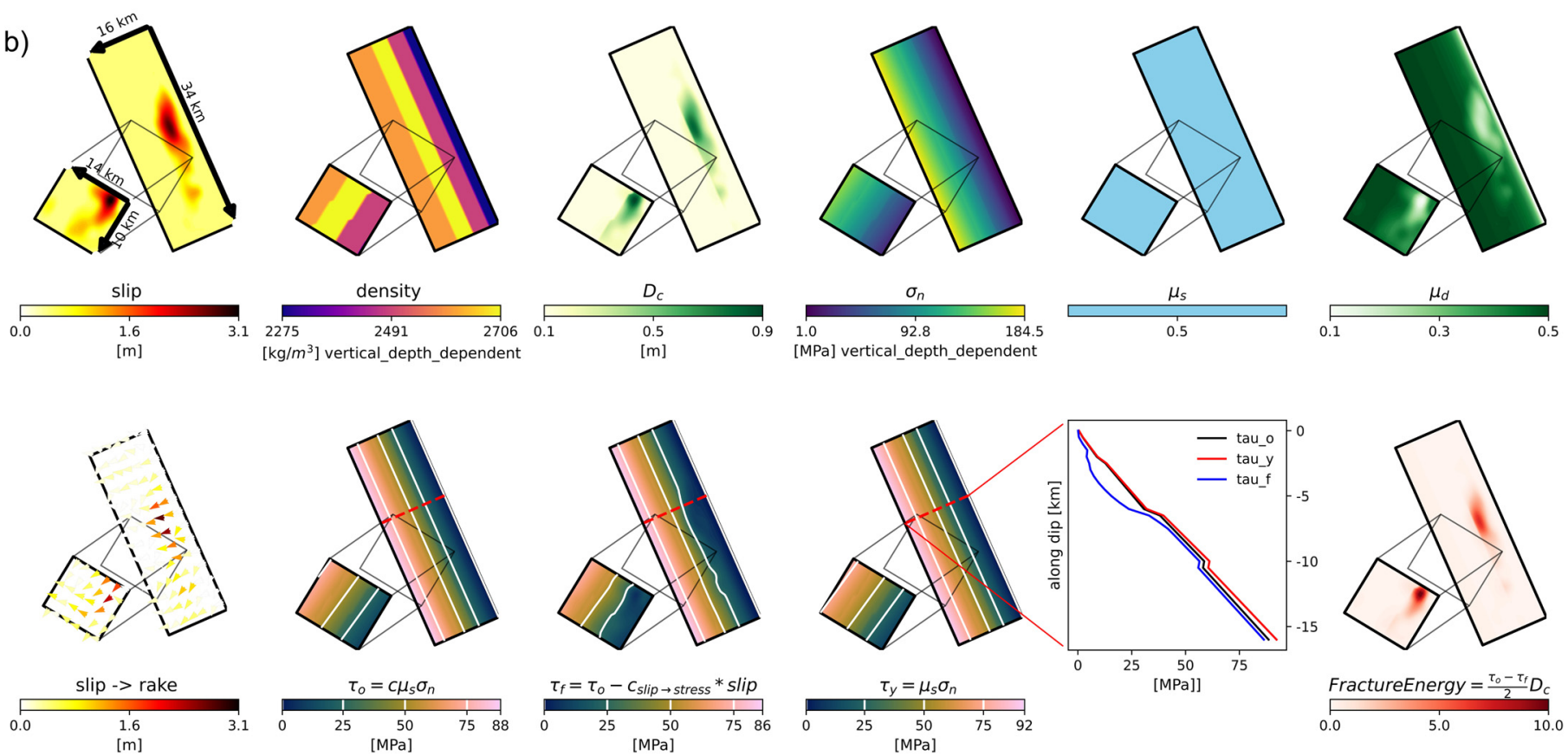

Fig. 5. Distribution of the dynamic rupture parameters of the two exemplary models of Family (B) (panel a) and (C) (panel b).

tribution of dynamic friction $\mu_{d}$ with values between 0.1 and 0.45 and constant $\mu_{s}=0.5$.

In computing the stress drop for both families (B) and (C), we slightly adapt the "S18" slip distribution at shallow depths $(<2 \mathrm{~km})$ to prevent fault reactivation due to rupture-free-surface interaction mediated by small normal stress. To further prevent near-surface supershear rupture in the uppermost $2 \mathrm{~km}$ we use higher values of $\mu_{s}(0.7)$ in Family (B) and we add frictional cohesion $c=2$ MPa to the yield strength $\left(\tau_{y}=\mu_{s} \sigma_{n}+c\right)$ in Family (C) as often assumed in dynamic rupture models (e.g., Harris et al., 2021). The resulting range of the dynamic parameters $\tau_{y}, \tau_{f}$ and $\tau_{0}$ for the representative models of the two families is very different (see Fig. 5).

As we have seen in Sec. 4.1 the choice of $D_{c}$ is fundamental. Yet, $D_{c}$ is one of the most difficult dynamic parameters to con- strain (Tinti et al., 2009; Guatteri and Spudich, 2000). We find in numerical experiments conducted for both heterogeneous Families (B) and (C) that a constant $D_{c}$ value on each fault plane does not allow realistic rupture dynamics. In fact, imposing a smaller $D_{c}\left(D_{c}<50 \mathrm{~cm}\right)$ on both fault planes leads to supershear rupture velocities. On the other hand, imposing larger $D_{c}$ values $\left(D_{c}>50 \mathrm{~cm}\right)$ tends to prevent the rupture from propagating spontaneously. These strong dynamic trade-offs are also due to the very small slip in and around the nucleation area (Gallovič et al., 2019). Thus, we here decide to assume $D_{c}$ proportional to slip (Tinti et al., 2009) which is a common assumption to ensure spontaneous rupture propagation. We note that the velocity toughening friction law of Andrews (2004), aiming at mimicking the effect of off-fault yielding, yields an equivalent linear scaling of $D_{c}$. Based on few trial simulations, we set $D_{c}=0.3 S_{\text {final }}\left(S_{\text {final }}\right.$ is the slip distribu- 
tion of the "S18" model) in the shallow part of the fault (down to $4.5 \mathrm{~km}$ depth) where the main patch of slip is located. Below $4.5 \mathrm{~km}$ depth, we set $D_{c}=0.1 S_{\text {final }}$, which aids spontaneous rupture to migrate to the shallow region of larger fault slip (see Fig. 5). The choice of $D_{c}$ affects the width of the cohesive zone, which has to be numerically well resolved (Wollherr et al., 2019). We limit $D_{c}$ to values larger than $0.02-0.06 \mathrm{~m}$ (depending on the family) which ensures that the median of the cohesive zone distribution remains numerically well resolved (Appendix A).

In Fig. 6 we show snapshots of fault slip (top) and slip rate (bottom) for one model of Family (B). Rupture propagates simultaneously on both fault planes. Moreover, rupture is also able to propagate beyond F210. The interaction of the main rupture front with the free surface produces back-propagating rupture fronts (interface waves, Dunham, 2005) of small amplitudes. The nucleation area (Sec. 3.3) results in a weak nucleation, as desired. The slip distribution features a large patch of slip of up to $3 \mathrm{~m}$ located just above the hypocenter on F155 with a dominant normal component, as well as a smaller patch of slip with similar maximum amplitude on the F210 fault with a dominant strike-slip component. The final slip distribution resembles the "S18" model, but is less heterogeneous. This arises mainly from the assumed proportionality between slip and stress drop as will become apparent in comparison to models initialized with the stress change computed from the "S18" model (see Sec. 4.2.2).

The rupture evolution of a representative dynamic rupture model belonging to Family (C), characterized by heterogeneous dynamic friction, is shown in Fig. 7 using fault slip and slip rates snapshots. The final slip distribution is very similar to the presented Family (B) model, despite the different dynamic conditions, due to comparable stress drop. Approximately, when neglecting dynamic under- and overshooting, the stress drop is indeed the same in both families, with heterogeneity in initial pre-stress parameterized as spatially variable $\mu_{s}$ or $\mu_{d}$ in Family B and C, respectively. Rupture speed, as well as the peak slip velocity, are also similar in the main area of slip. The Family (C) model features a slightly higher rupture velocity than the Family (B) model towards the northern end of the main fault. Again, this model allows the rupture to propagate behind the secondary fault.

The total inferred seismic moments are $1.05 \times 10^{19} \mathrm{Nm}$ and $1.3 \times 10^{19} \mathrm{Nm}$ for the representative models of Family (B) and (C), respectively. These values agree with the seismic moment inferred from kinematic inversion in (Scognamiglio et al., 2018) $\left(0.88 \times 10^{19} \mathrm{~N} \mathrm{~m}\right)$. The average fracture energy computed accounting only for fault cells with slip larger than $20 \%$ of average slip is $0.7 \mathrm{M} \mathrm{J} / \mathrm{m}^{2}$ for Family (B) and $0.61 \mathrm{M} \mathrm{J} / \mathrm{m}^{2}$ for Family (C). These averages are smaller than those obtained for models of Family (Hom) (Section 4.1) and consistent with proposed scaling laws between fracture energy and seismic moment (Viesca and Garagash, 2015; Tinti et al., 2005).

Fig. 8 compares synthetic velocity waveforms, with selected observed data in the near-source region. We obtain a surprisingly good fit in both amplitude and phase for both families, given our synthetics are not resulting from a dynamic source inversion. We underline that no static correction has been applied. Moreover, the synthetics of the two families are very similar to each other. Synthetic waveforms at the CNE station, located northwest of the main patch, have similar pulses and amplitudes to the recorded data in both models but are slightly delayed indicating directivity effects not fully captured in either scenario.

\subsubsection{Kinematically inferred stress change}

We now present models that belong to Family (B) and (C) in which the stress drop distribution is initialized from the stress change kinematically computed from the "S18" model. We call these models "stress change" models. The stress change models differ from the previously presented models only in their (potential) stress drop distribution. Fig. 9 shows the imposed heterogeneous distributions of $\mu_{s}$ and $\mu_{d}$ for two models belonging to Families (B) and (C), respectively. Both friction parameters are distributed within the same range $(0.2-0.7)$ but more heterogeneous compared to the models of Section 4.2.1. Note that the large values of $\mu_{d}(\approx 0.7)$ in Fig. 9 are fictitious since they are located in areas where rupture does not propagate. Both stress change models show a more heterogeneous distribution also of all other dynamic and kinematic parameters, which is reflected in the complex rupture history shown in Figures S4 and S5. In these models the peak slip on F210 is higher, while on average the final slip distribution is more similar to the original model "S18" than the models presented in Figs. 6 and 7. Also, the rupture evolution is more complex than the circular propagation assumed in the kinematic model, due to the highly heterogeneous pre-stress distribution in the stress-change models.

In Fig. 9 we show the waveform fits for these models. Both stress change models align well with observations. Synthetics of the two models are again similar to each other although differences are more clearly noticeable than in the models shown previously. The more pronounced variability between the models of the two families is expected because they have different and complex slip rate histories.

\subsubsection{Geodetic validation}

Even if we here do not aim at identifying a best dynamic model for the Norcia earthquake, we validate all four exemplary heterogeneous dynamic rupture models also with geodetic GPS and InSAR data. We compare in Fig. 10 the synthetic deformation along line of sight for the descending and ascending ALOS2 InSAR data and the synthetic coseismic displacements with GPS observations (Cheloni et al., 2017).

The target "S18" model, inverted from strong-motion and GPS data, offers, as expected, the best fit to the GPS data. The dynamic rupture models having the same stress drop assumption yield similar geodetic fits. The "stress change" models, having slip distributions very similar to the original "S18" model, offer the best fit for InSAR data, and reproduce the GPS reasonably well in amplitude and direction, except for a large observed displacement in the footwall region.

Models inferred by assuming stress drop proportional to slip (Section 4.2.1), show in general the largest deformation values, still consistent with inversion results, but at worse orientation. This is mainly due to their slip distributions, which reproduce the largescale features of the target model but not its shallow smaller-scale heterogeneities. Comparison with both ascending and descending InSAR data yields similar conclusions (Fig. 10 and Figure S8). Note that this dataset can only be discussed qualitatively, as the observed data contain also the deformation produced by the Mw 5.9 Visso earthquake.

While our results suggest the existence of dynamic models within both heterogeneous families able to support the dynamic viability of the "S18" kinematic model, model validation with seismological and geodetic data does not identify a preferred family of models. Additional constraints are needed to assign heterogeneities to dynamic parameters, e.g. using friction values consistent with rock properties in the area.

\section{Discussion}

We present several dynamic rupture models for the Norcia earthquake to assess if the kinematic model "S18" proposed by Scognamiglio et al. (2018) is dynamically viable (i.e. if the earthquake can propagate spontaneously on both faults). To this end, 

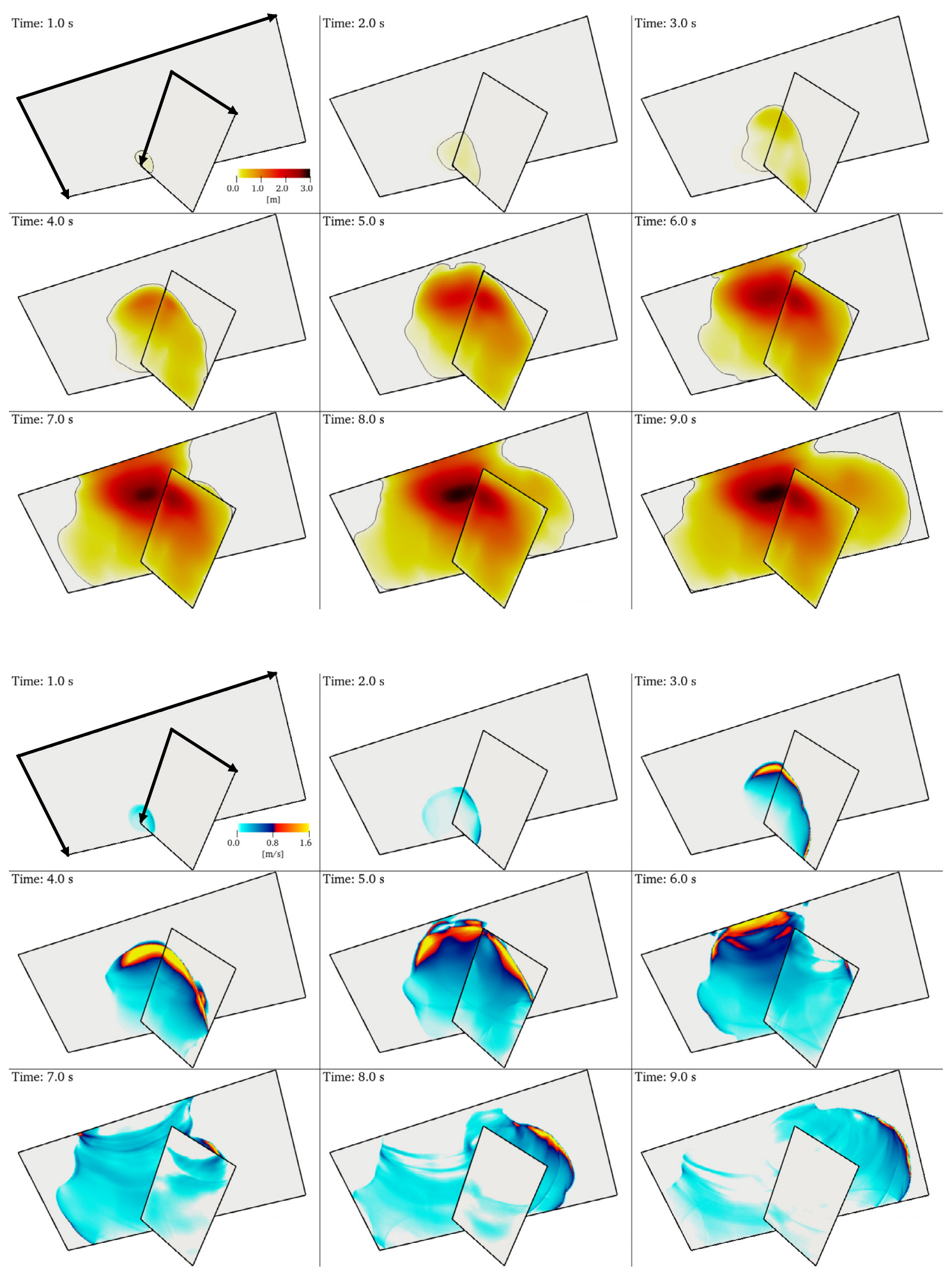

Fig. 6. Dynamics of the exemplary model belonging to Family (B) inferred by assuming stress drop proportional to slip. Snapshots, every one second, of slip (m, top) and slip rate $(\mathrm{m} / \mathrm{s}$, bottom). Corresponding animations are available in supplementary material.

we design families of dynamic parameters. Family (Hom), the simplest possible distribution of dynamic parameters, allows us to dynamically validate the fault geometry and the average rake val- ues inferred in the "S18" model. Specifically, we find parameter sets that allow for simultaneous spontaneous dynamic rupture of both fault planes (even if the secondary fault is dynamically more 

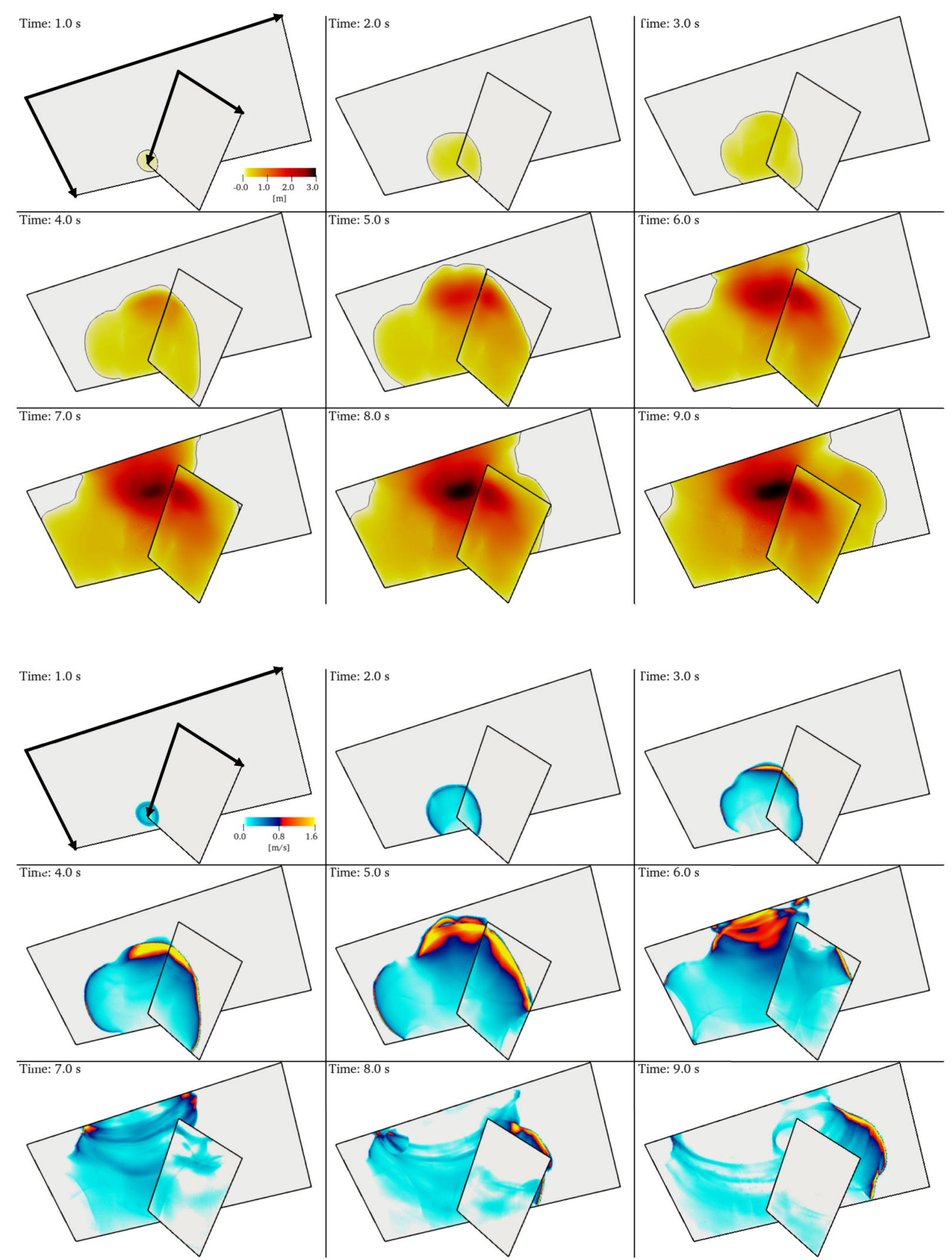

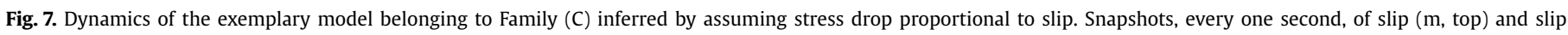
rate $(\mathrm{m} / \mathrm{s}$, bottom). Corresponding animations are available in supplementary material.

challenging to activate). However, homogeneous dynamic conditions lead to earthquake scenarios not agreeing well with observations.
The models of Family (B) and (C) with spatially heterogeneous dynamic parameters permit to dynamically retrieve slip distributions similar to model "S18", yielding a satisfactory fit of the 


\section{stress proportional to slip models}

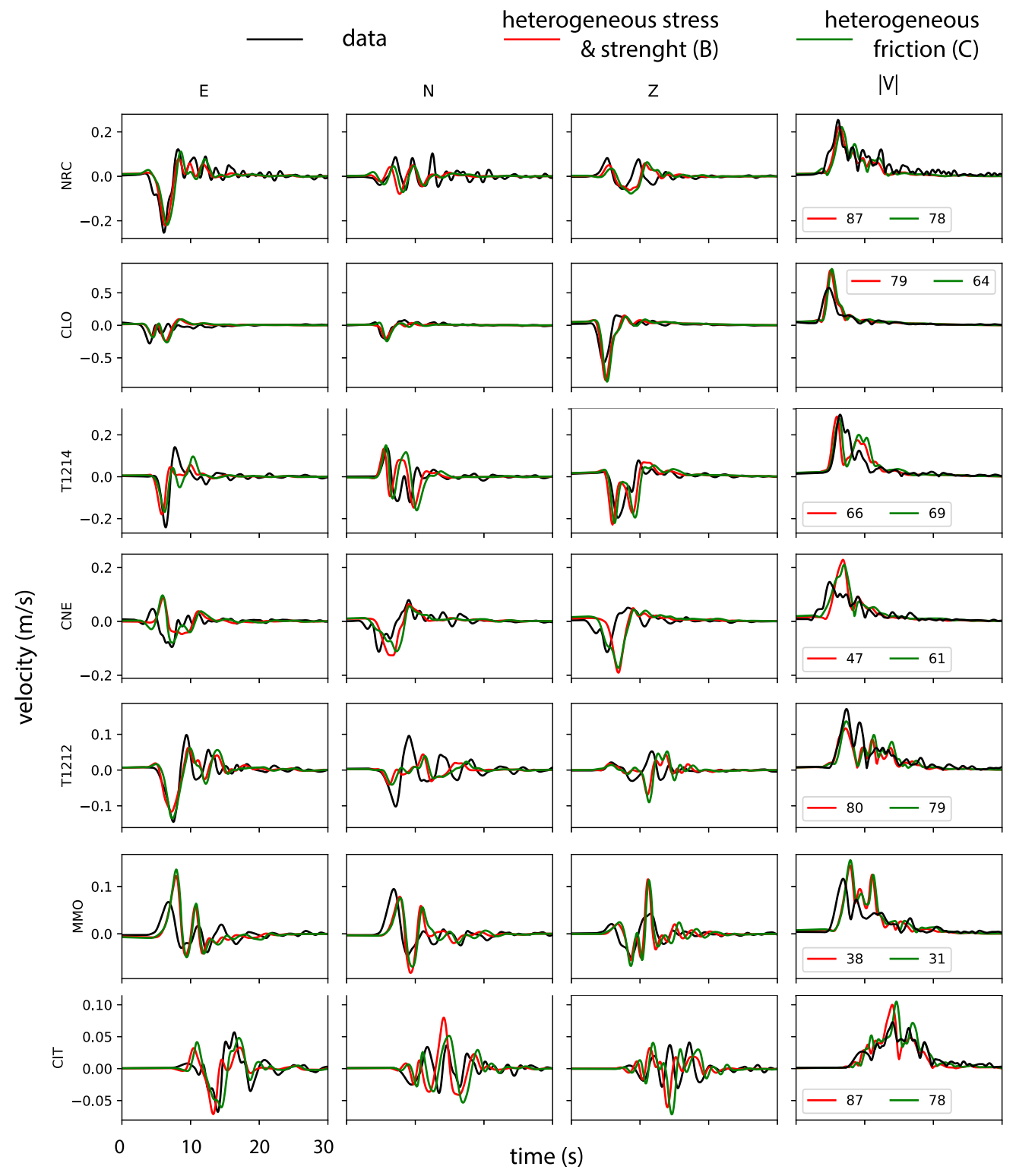

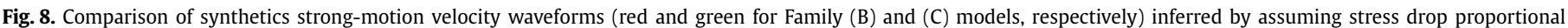

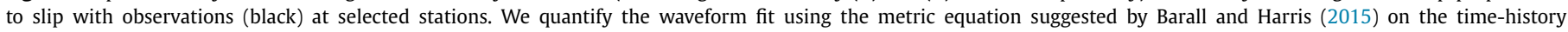

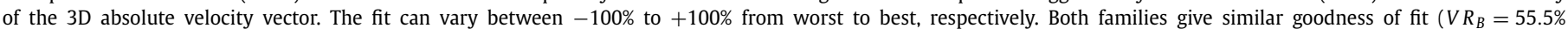

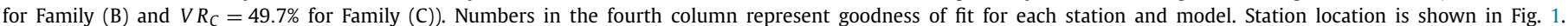
Additional waveform comparisons are shown in Figure S2 and S3.

observed waveforms and geodetic observations. We suggest the existence of suites of dynamic models in both families that are able to validate the target kinematic model.

However, the dynamic conditions of Family (B) and (C) are very different. In Family (B), we assume constant dynamic friction $\left(\mu_{d}=0.2\right)$ and heterogeneous static friction, which varies between $\mu_{s}=0.2$ and 0.7 . In Family (C), we assume constant static friction (in the showed model, we assume $\mu_{s}=0.5$ ) while the dynamic friction is heterogeneous and varies between $\mu_{d}=0.1$ and 0.45 .

Geological data and results from laboratory experiments provide strong evidence for structural and frictional heterogeneities within crustal faults (Collettini et al., 2019). However, the different dynamic parameter assumptions made for Families (B) and (C) have implications for the physical processes occurring on the fault plane during the coseismic stage. In particular, the choice of reliable friction coefficients may be related to the rocks where the event nucleates, propagates, and finally generates the large slip patches.

For the Norcia earthquake, the integration of seismic reflection profiles with seismological data shows that the mainshock nucleated within the Triassic Evaporites and propagated through the overlaying carbonates (Porreca et al., 2018). The Triassic Evaporites consist of anhydrites and dolostones and laboratory data on these fault rocks show static friction in the range of 0.5-0.6 (Scuderi et al., 2013) with a reduction to 0.4 with increasing temperatures. In addition, the main patch of slip seems to be located within carbonates (Scognamiglio et al., 2018; Porreca et al., 2018), where the static friction is around the Byerlee's values (0.6) and dynamic friction at high slip rates can be as low as 0.2 (e.g., De Paola et al., 2015). Experiments conducted at high slip velocities $(>1 \mathrm{~m} / \mathrm{s})$ (Di Toro et al., 2011) show that dynamic friction of different rocks ranges between 0.1 and 0.4 . Static friction as low as 0.3-0.2 can 


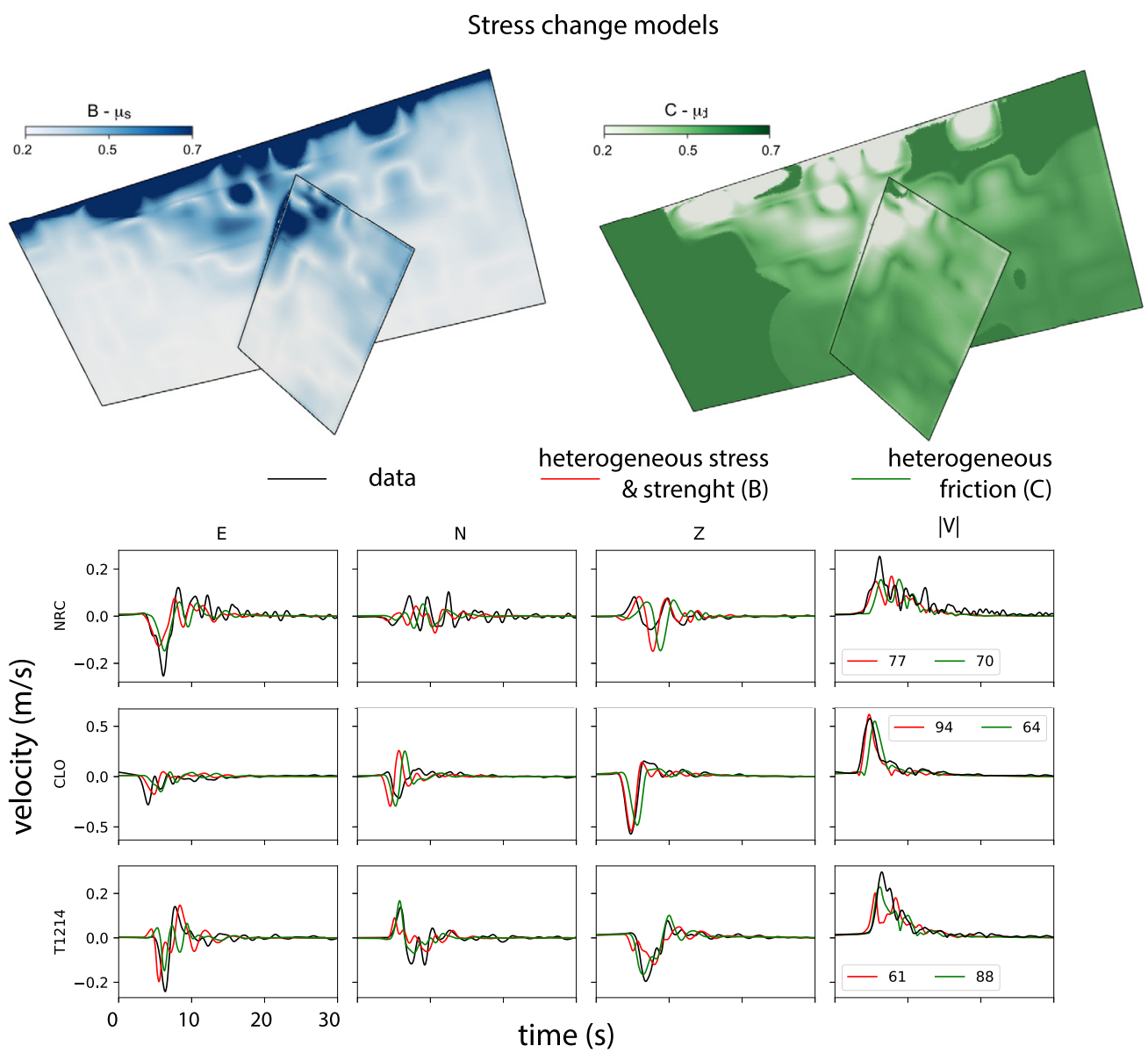

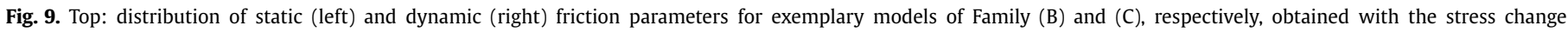

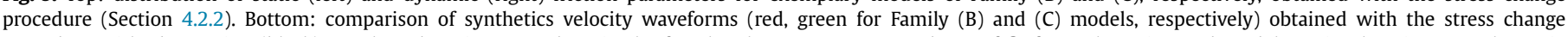

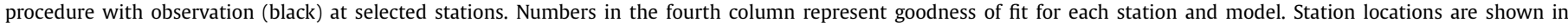
Fig. 1. Additional waveform comparisons are shown in Figure S6 and S7.

be found only in clay-rich rocks (e.g., phyllosilicates). However, friction experiments on carbonates-clay mixtures show that the increase of clay content promotes a clear transition from velocity weakening to velocity strengthening behavior (Ruggieri et al., 2021). In consideration of these experimental values, the models of Family (B) may be plausible when considering rocks rich in phyllosilicates. Such low static friction values retrieved for Family (B) are located in and around the nucleation zone. Since these conditions may lead to velocity strengthening, this area would be less prone to nucleate (Ruggieri et al., 2021). Finding clay-rich rocks at depths similar to the hypocentral depth is unlikely (Porreca et al., 2018). Since small slip in the nucleation area is a specific earthquake characteristic, we may hypothesize that weak nucleation can result from pre-seismic creep.

Following the results of Porreca et al. (2018) and laboratory values, it seems that models belonging to Family (C) are promising candidates to represent the friction values of the seismogenic area in the Central Apennines. This family shows the lowest values of dynamic friction (0.1) in the areas of highest slip rate, consistent with laboratory experiments, while the highest dynamic friction values characterize areas of small slip.

While we here show that the S18 kinematic model can constrain reasonable dynamic rupture scenarios under certain assumptions (e.g., assuming weak nucleation), we note that both, kinematic and dynamic earthquake source models, may be highly nonunique when considered in isolation. Due to the vast size of the null space of the inverse problem and incomplete data coverage, kinematic combinations of source parameters may be acceptable that include opposite rake angles of multiple faults and fault geometries that may not favor dynamic fault interaction. On the other hand, dynamic trade-offs, e.g., between strength excess and slip-weakening distance, challenge an intuitive assessment of the physical consistency of a given kinematic model. We believe that adding physics-based constraints (i.e., by the assumed friction law) and combining dynamic rupture modeling and kinematic source inversion will reduce uncertainty of both kinds of proposed models.

\section{Conclusions}

We propose families of dynamic models for the $M_{w} 6.5$ October 30th, 2016 Norcia earthquake that aim to reproduce the main characteristics of the "S18" kinematic model (inferred by Scognamiglio et al., 2018) and to assess its mechanical viability. We detail representative models of two families: either with constant dynamic friction coefficient and heterogeneous initial stress and yield strength or with constant static friction coefficient, homogeneous depth-dependent initial stress, and heterogeneous dynamic friction coefficient.

In addition to the goodness of fit of seismic waveforms and geodetic deformation (GPS and InSAR) and the ability to reproduce characteristics of the target kinematic model (such as the slip distribution), we propose that geological constraints, e.g. ensuring compatibility of the assumed friction values with experimental values from near-fault rocks, can help to discriminate among plausible dynamic rupture scenarios. 

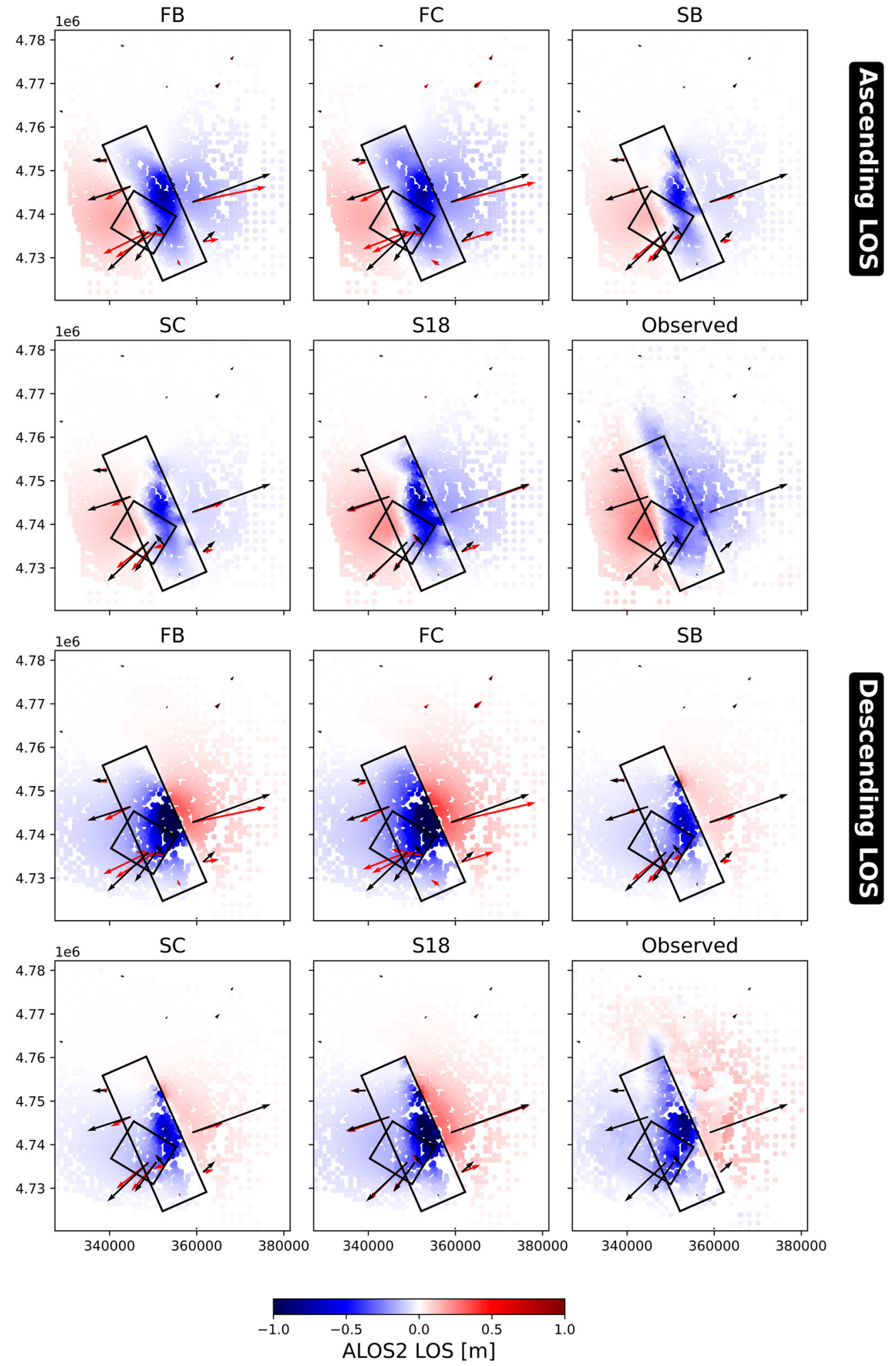

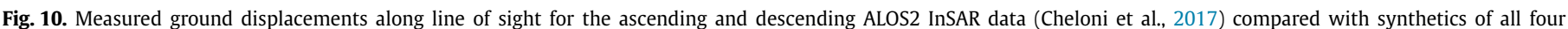

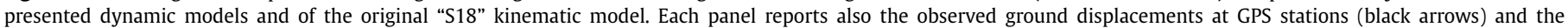

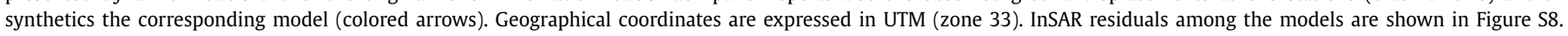

Despite the limited resolution of seismological and geodetic data, we believe that future efforts shall be directed towards a new generation of dynamic models of real events including constraints from interdisciplinary geophysical observations. For example, using models of Family (B) or (C), the static and dynamic friction parameters may be chosen based on available geological and lithological constraints, while future high-resolution, near-fault seismic and geodetic data can help to constrain fault characteristics, e.g. $D_{c}$, and relative initial shear loading, in-situ. Reducing the tradeoffs among the dynamic parameters by improving the resolution 
of the seismological data and the knowledge of friction properties of fault rocks are definitely ingredients to combine.

The developed approach can be readily applied to various types of earthquakes using kinematic models to constrain dynamic rupture scenarios and enhance data-driven approaches with physicsbased implications.

\section{CRediT authorship contribution statement}

Elisa Tinti: Conceptualization, Data curation, Formal analysis, Investigation, Writing - original draft, Writing - review \& editing. Emanuele Casarotti: Data curation, Formal analysis, Investigation, Writing - original draft, Writing - review \& editing. Thomas Ulrich: Methodology, Data curation, Validation, Software, Writing - review \& editing. Taufiqurrahman: Software, Writing - review \& editing. Duo Li: Methodology, Writing - review \& editing. Alice-Agnes Gabriel: Conceptualization, Funding acquisition, Investigation, Methodology, Supervision, Resources, Validation, Software, Writing - review \& editing. All authors approve on the submitted article.

\section{Declaration of competing interest}

The authors declare that they have no known competing financial interests or personal relationships that could have appeared to influence the work reported in this paper.

\section{Data and resources}

SeisSol is openly available at https://github.com/SeisSol/SeisSol. We use commit 24b71e4b0b1501782f0369c068dfcc99f57d1bcb. All simulation input files and the jupyter notebooks are accessible at https://github.com/git-taufiq/NorciaMultiFault.

\section{Acknowledgements}

We would like to thank M. Scuderi and C. Collettini for helpful discussions. We thank the editor R. Bendick, reviewers R. Harris and T. Ragon for their helpful and detailed reviews. T.U., T., D.L., and A.-A. Gabriel are supported by the European Research Council (ERC) under the European Union's Horizon 2020 research and innovation programme (TEAR, agreement No. 852992 and ChEESE, grant no. 823844), the German Research Foundation (DFG project grants no. GA 2465/2-1 and GA 2465/3-1) and by KAUST-CRG (grant no. ORS-2017-CRG6 3389.02). E.T. was supported by Progetti di Ricerca Sapienza (RM120172A2EAC019). Computing resources were provided by the Leibniz Supercomputing Centre (LRZ, project no. pr63qo on SuperMUC-NG).

\section{Appendix A. Numerical method and computational mesh}

We use SeisSol, a powerful open-source software package (https://github.com/SeisSol/SeisSol), to perform dynamic rupture simulations at the supercomputer SuperMUC-NG at the Leibniz Supercomputing Centre, Germany. SeisSol solves the 3-D elastodynamic problem of spontaneous frictional failure across prescribed fault surfaces nonlinearly coupled to seismic wave propagation based on an the Arbitrary high-order accurate DERivative Discontinuous Galerkin method (ADER-DG, Dumbser and Käser, 2006; Heinecke et al., 2014).

SeisSol reaches scalable performance up to several thousand nodes on modern supercomputers (Heinecke et al., 2014; Uphoff et al., 2017) and has been applied in large-scale, data-integrated earthquake models, including crustal events (Wollherr et al., 2019; Ulrich et al., 2019), intraplate (Palgunadi et al., 2020) and megathrust earthquakes (Uphoff et al., 2017). SeisSol uses unstructured tetrahedral meshes enabling geometrically complex models, such as branching and intersecting faults (Pelties et al., 2014). Aided by a clustered local time-stepping scheme, mesh resolution can be adapted to ensure fine sampling of the faults while satisfying the requirements regarding numerical dispersion of pure wave propagation away from the fault. End-to-end computational optimizations (Uphoff et al., 2017), allows for high efficiency on high-performance computing infrastructure. SeisSol is verified in a wide range of community benchmarks (Pelties et al., 2014) by the SCEC/USGS Dynamic Rupture Code Verification project (Harris et al., 2018).

Our model domain is discretized into an unstructured computational mesh of four-node linear tetrahedral elements. We use an on-fault spatial discretization $h$ of $250 \mathrm{~m}$ for all models shown in the paper (corresponding to $\sim 16$ million elements). In the volume, we parametrize the mesh size based on the velocity structure: we allow 3 cells per wavelength of shear waves to ensure resolving a maximum frequency of at least $1 \mathrm{~Hz}$. In most of our simulations, we use basis functions of polynomial order $p=4$ which leads to fifth-order numerical accuracy in time and space. In SeisSol, each triangular fault interface is sub-sampled by $(p+2)^{2}$ Gaussian integration points.

We ensure all simulation results are sufficiently resolved by following the procedure established in Wollherr et al. (2018), following Day et al. (2005). We measure the cohesive zone size, the region behind the rupture front where the fault strength drops from its static to dynamic level, everywhere on both faults. In a purely elastic setup with depth-dependent heterogeneous initial conditions it is sufficient to resolve the median cohesive zone size $\Lambda$ by $\approx 1-2$ elements (for $p=5$ ) or $\approx 2-3$ elements (for $p=4$ ). With $h=250 \mathrm{~m}$ we ensure that the median cohesive zone size is correctly resolved $(\Lambda>600 \mathrm{~m})$ for all our models, except Family (C).

Adopting the same mesh for Family (C) models, we increase the resolution by using $p=5$ (order 6 space-time accuracy). We verify that the fault dynamics of the more heterogeneous Family $\mathrm{C}$ models are sufficiently resolved by comparing the on-fault results with results from a finer mesh of fault mesh size $h=100 \mathrm{~m}$ (corresponding to $\sim 33$ million elements and median $\Lambda=253 \mathrm{~m}$ ). Rupture arrival time, peak slip-rate, and final slip differ by about $1.5 \%, 1.4 \%$ and $1 \%$, respectively, between these two simulations. Such errors are well within the recommended criteria of (Day et al., 2005).

Simulating $30 \mathrm{~s}$ of each earthquake scenario using 5 th order accuracy in space and time and on fault mesh size $h=250 \mathrm{~m}$ requires about $600 \mathrm{CPU}$ hours in single precision.

\section{Appendix B. Model validation data}

The $M_{w} 6.5$ October 30th, 2016 Norcia earthquake has been recorded by a dense network of strong-motion stations (Fig. 1), by Global Positioning System (GPS) stations, and by ALOS-2 satellites. The strong motion stations belong to the National Accelerometric Network (http://ran.protezionecivile.it) of the Italian Department of Civil Protection and the National Seismic Network of INGV (Michelini et al., 2016). Strong motion recordings were processed to remove the instrument response, band-pass filtered in the frequency range of $0.02-0.5 \mathrm{~Hz}$ (Butterworth filter with 2 passes 2 poles), and integrated to obtain ground velocity waveforms. The location of the used stations is shown in Fig. 1. The maximum stationepicenter distance is within $45 \mathrm{~km}$. These recorded waveforms are compared with synthetics computed using SeisSol, filtered in the same frequency band. The three-components coseismic displacements recorded by campaign GPS stations have been downloaded from the RING website (http://ring.gm.ingv.it), and the location of the closest stations is shown in Fig. 10. 
The satellite data (InSAR) acquired by the ascending and descending orbits along the line of sight of ALOS-2 (Cheloni et al., 2017) has a time interval covering both the October 30th Norcia event and the $M_{w} 5.9$ Visso earthquake (October 26th). It does not allow discrimination between the surface displacement effects produced by the two earthquakes separately in the northern region (Fig. 10). All these data-set have been used in this work to validate the proposed dynamic models.

\section{Appendix C. Velocity structure}

We adopt the 1D layered model for the Central Apennines of Herrmann et al. (2011) (nnCIA model), constrained by deep crustal profiles, surface-wave dispersion, and teleseismic P-wave receiver functions. This model consists of five crustal layers above the Moho, including a thin $(1.5 \mathrm{~km})$ shallow layer with a relatively low shear wave velocity of $2.14 \mathrm{~km} / \mathrm{s}$ and a velocity inversion at a depth of $4.5 \mathrm{~km}$ (see Fig. 2 and Figure S1). The model is routinely adopted for moment tensor inversion for Italian earthquakes and kinematic finite fault inversions in the Apennines Region, including the "S18" model.

\section{Appendix D. Supplementary material}

Supplementary material related to this article can be found online at https://doi.org/10.1016/j.epsl.2021.117237.

\section{References}

Ando, R., Kaneko, Y., 2018. Dynamic rupture simulation reproduces spontaneous multifault rupture and arrest during the $2016 \mathrm{M}$ w 7.9 Kaikoura earthquake. Geophys. Res. Lett. 45, 12,875-12,883. https://doi.org/10.1029/2018GL080550.

Andrews, D.J., 1976. Rupture propagation with finite stress in antiplane strain. J. Geophys. Res. 81, 3575-3582. https://doi.org/10.1029/JB081i020p03575.

Andrews, D.J., 1980. A stochastic fault model: 1. Static case. Technical Report B7. https://doi.org/10.1029/JB085iB07p03867.

Andrews, D.J., 2004. Rupture models with dynamically determined breakdown displacement. Bull. Seismol. Soc. Am. 94, 769-775. https://doi.org/10.1785/ 0120030142.

Aochi, H., 2018. Dynamic asymmetry of normal and reverse faults due to constrained depth-dependent stress accumulation. Geophys. J. Int. 215, 2134-2143. https://doi.org/10.1093/gji/ggy407.

Aochi, H., Twardzik, C., 2020. Imaging of seismogenic asperities of the 2016 ML 6.0 amatrice, central Italy, earthquake through dynamic rupture simulations. Pure Appl. Geophys. 177, 1931-1946. https://doi.org/10.1007/s00024-019-02199-z.

Bai, K., Ampuero, J.P., 2017. Effect of seismogenic depth and background stress on physical limits of earthquake rupture across fault step overs. J. Geophys. Res., Solid Earth 122, 10,280-10,298. https://doi.org/10.1002/2017JB014848.

Barall, M., Harris, R.A., 2015. Metrics for comparing dynamic earthquake rupture simulations. Seismol. Res. Lett. 86, 223-235. https://doi.org/10.1785/ 0220140122.

Barenblatt, G.I., 1959. The formation of equilibrium cracks during brittle fracture. General ideas and hypotheses. Axially-symmetric cracks. J. Appl. Math. Mech. 23, 622-636. https://doi.org/10.1016/0021-8928(59)90157-1.

Bhat, H.S., Olives, M., Dmowska, R., Rice, J.R., 2007. Role of fault branches in earthquake rupture dynamics. J. Geophys. Res. 112, B11309. https://doi.org/10.1029/ 2007JB005027.

Bonini, L., Basili, R., Burrato, P., Cannelli, V., Fracassi, U., Maesano, F.E., Melini, D., Tarabusi, G., Tiberti, M.M., Vannoli, P., Valensise, G., 2019. Testing different tectonic models for the source of the Mw 6.5, 30 October 2016, Norcia earthquake (Central Italy): a youthful normal fault, or negative inversion of an old thrust? Tectonics 38, 990-1017. https://doi.org/10.1029/2018TC005185.

Byerlee, J., 1978. Friction of rocks. In: Rock Friction and Earthquake Prediction. Birkhäuser, Basel, pp. 615-626. https://link.springer.com/chapter/10.1007/978-30348-7182-2_4.

Causse, M., Dalguer, L.A., Mai, P.M., 2014. Variability of dynamic source parameters inferred from kinematic models of past earthquakes. Geophys. J. Int. 196, 1754-1769. https://doi.org/10.1093/gji/ggt478.

Cheloni, D., De Novellis, V., Albano, M., Antonioli, A., Anzidei, M., Atzori, S., Avallone, A., Bignami, C., Bonano, M., Calcaterra, S., Castaldo, R., Casu, F., Cecere, G., De Luca, C., Devoti, R., Di Bucci, D., Esposito, A., Galvani, A., Gambino, P., Giuliani, R., Lanari, R., Manunta, M., Manzo, M., Mattone, M., Montuori, A., Pepe, A., Pepe, S., Pezzo, G., Pietrantonio, G., Polcari, M., Riguzzi, F., Salvi, S., Sepe, V., Serpelloni, E., Solaro, G., Stramondo, S., Tizzani, P., Tolomei, C., Trasatti, E., Valerio, E., Zinno, I., Doglioni, C., 2017. Geodetic model of the 2016 Central Italy earthquake sequence inferred from InSAR and GPS data. Geophys. Res. Lett. 44, 6778-6787. https://doi.org/10.1002/2017GL073580.

Chiaraluce, L., Di Stefano, R., Tinti, E., Scognamiglio, L., Michele, M., Casarotti, E., Cattaneo, M., De Gori, P., Chiarabba, C., Monachesi, G., Lombardi, A., Valoroso, L., Latorre, D., Marzorati, S., 2017. The 2016 central Italy seismic sequence: a first look at the mainshocks, aftershocks, and source models. Seismol. Res. Lett. 88. https://doi.org/10.1785/0220160221.

Cocco, M., Tinti, E., 2008. Scale dependence in the dynamics of earthquake propagation: evidence from seismological and geological observations. Earth Planet. Sci. Lett. 273, 123-131.

Collettini, C., Tesei, T., Scuderi, M.M., Carpenter, B.M., Viti, C., 2019. Beyond Byerlee friction, weak faults and implications for slip behavior. Earth Planet. Sci. Lett. 519, 245-263. https://doi.org/10.1016/j.epsl.2019.05.011.

Day, S.M., Dalguer, L.A., Lapusta, N., Liu, Y., 2005. Comparison of finite difference and boundary integral solutions to three-dimensional spontaneous rupture. J. Geophys. Res., Solid Earth 110, 1-23. https://doi.org/10.1029/2005JB003813.

De Paola, N., Holdsworth, R.E., Viti, C., Collettini, C., Bullock, R., 2015. Can grain size sensitive flow lubricate faults during the initial stages of earthquake propagation? Earth Planet. Sci. Lett. 431, 48-58. https://doi.org/10.1016/j.epsl.2015.09. 002.

Di Toro, G., Han, R., Hirose, T., De Paola, N., Nielsen, S., Mizoguchi, K., Ferri, F., Cocco, M., Shimamoto, T., 2011. Fault lubrication during earthquakes. Nature 471, 494-498. https://doi.org/10.1038/nature09838.

Dieterich, J.H., 1979. Modeling of rock friction: 1. Experimental results and constitutive equations. J. Geophys. Res. 84, 2161. https://doi.org/10.1029/ JB084iB05p02161.

Douilly, R., Oglesby, D.D., Cooke, M.L., Hatch, J.L., 2020. Dynamic models of earthquake rupture along branch faults of the eastern San Gorgonio pass region in California using complex fault structure. Geosphere 16, 474-489. https:// doi.org/10.1130/GES02192.1.

Dumbser, M., Käser, M., 2006. An arbitrary high-order discontinuous Galerkin method for elastic waves on unstructured meshes - II. The three-dimensional isotropic case. Geophys. J. Int. 167, 319-336. https://doi.org/10.1111/j.1365246X.2006.03120.x.

Dunham, E.M., 2005. Dissipative interface waves and the transient response of a three-dimensional sliding interface with Coulomb friction. J. Mech. Phys. Solids 53, 327-357. https://doi.org/10.1016/j.jmps.2004.07.003.

Fukuyama, E., Mikumo, T., 1993. Dynamic rupture analysis: inversion for the source process of the 1990 Izu-Oshima, Japan, earthquake $(M=6.5)$. J. Geophys. Res., Solid Earth 98, 6529-6542. https://doi.org/10.1029/92JB02451.

Gabriel, A.A., Ampuero, J.P., Dalguer, L.A., Mai, P.M., 2012. The transition of dynamic rupture styles in elastic media under velocity-weakening friction. J. Geophys. Res., Solid Earth 117, 9311. https://doi.org/10.1029/2012JB009468.

Gallovič, F., Valentová Ampuero, J.P., Gabriel, A.A., 2019. Bayesian dynamic finitefault inversion: 2. Application to the $2016 \mathrm{Mw} 6.2$ amatrice, Italy, earthquake. J. Geophys. Res., Solid Earth 124, 6970-6988. https://doi.org/10.1029/ 2019 JB017512.

Galvez, P., Ampuero, J.P., Dalguer, L.A., Somala, S.N., Nissen-Meyer, T., 2014. Dynamic earthquake rupture modelled with an unstructured 3-D spectral element method applied to the 2011 M9 Tohoku earthquake. Geophys. J. Int. 198, 1222-1240. https://doi.org/10.1093/gji/ggu203.

Goto, H., Sawada, S., 2010. Trade-offs among dynamic parameters inferred from results of dynamic source inversion. Bull. Seismol. Soc. Am. 100, 910-922. https:// doi.org/10.1785/0120080250.

Guatteri, M., Spudich, P., 2000. What can strong-motion data tell us about slipweakening fault-friction laws? Bull. Seismol. Soc. Am. 90, 98-116. https:// doi.org/10.1785/0119990053.

Harris, R.A., Aagaard, B., Barall, M., Ma, S., Roten, D., Olsen, K., Duan, B., Liu, D., Luo, B., Bai, K., Ampuero, J.P., Kaneko, Y., Gabriel, A.A., Duru, K., Ulrich, T., Wollherr, S., Shi, Z., Dunham, E., Bydlon, S., Zhang, Z., Chen, X., Somala, S.N., Pelties, C., Tago, J., Cruz-Atienza, V.M., Kozdon, J., Daub, E., Aslam, K., Kase, Y., Withers, K., Dalguer, L., 2018. A suite of exercises for verifying dynamic earthquake rupture codes. Seismol. Res. Lett. 89, 1146-1162. https://doi.org/10.1785/0220170222.

Harris, R.A., Barall, M., Lockner, D.A., Moore, D.E., Ponce, D.A., Graymer, R.W., Funning, G., Morrow, C.A., Kyriakopoulos, C., Eberhart-Phillips, D., 2021. A geology and geodesy based model of dynamic earthquake rupture on the Rodgers CreekHayward-Calaveras fault system, California. J. Geophys. Res., Solid Earth 126, e2020JB020577. https://doi.org/10.1029/2020jb020577.

Haskell, N.A., 1964. Total energy and energy spectral density of elastic wave radiation from propagating faults. Bull. Seismol. Soc. Am. 54, 1811-1841.

Heinecke, A., Breuer, A., Rettenberger, S., Bader, M., Gabriel, A.A., Pelties, C., Bode, A., Barth, W., Liao, X.K., Vaidyanathan, K., Smelyanskiy, M., Dubey, P., 2014. Petascale high order dynamic rupture earthquake simulations on heterogeneous supercomputers. In: International Conference for High Performance Computing, Networking, Storage and Analysis. SC. IEEE Computer Society, pp. 3-14.

Herrmann, R.B., Malagnini, L., Munafò, I., 2011. Regional moment tensors of the 2009 L'Aquila earthquake sequence. Bull. Seismol. Soc. Am. 101, 975-993. https://doi. org/10.1785/0120100184.

Kyriakopoulos, C., Oglesby, D.D., Rockwell, T.K., Meltzner, A.J., Barall, M., Fletcher, J.M., Tulanowski, D., 2019. Dynamic rupture scenarios in the Brawley Seis- 
mic Zone, Salton Trough, Southern California. J. Geophys. Res., Solid Earth 124, 3680-3707. https://doi.org/10.1029/2018JB016795.

Lambert, V., Lapusta, N., Perry, S., 2021. Propagation of large earthquakes as selfhealing pulses or mild cracks. Nature 591, 252-258. https://doi.org/10.1038/ s41586-021-03248-1.

Ma, S., Beroza, G.C., 2008. Rupture dynamics on a bimaterial interface for dipping faults. Bull. Seismol. Soc. Am. 98, 1642-1658. https://doi.org/10.1785/ 0120070201.

Mariucci, M.T., Montone, P., 2020. IPSI 1.4, database of Italian present-day stress indicators. https://doi.org/10.13127/IPSI.1.4.

Michele, M., Chiaraluce, L., Di Stefano, R., Waldhauser, F., 2020. Fine-scale structure of the 2016-2017 central Italy seismic sequence from data recorded at the Italian national network. J. Geophys. Res., Solid Earth 125, 1-26. https:// doi.org/10.1029/2019JB018440.

Michelini, A., Margheriti, L., Cattaneo, M., Cecere, G., D’Anna, G., Delladio, A., Moretti, M., Pintore, S., Amato, A., Basili, A., Bono, A., Casale, P., Danecek, P., Demartin, M., Faenza, L., Lauciani, V., Giovanni Mandiello, A., Marchetti, A., Marcocci, C., Mazza, S., Mariano Mele, F., Nardi, A., Nostro, C., Pignone, M., Quintiliani, M., Rao, S., Scognamiglio, L., Selvaggi, G., 2016. The Italian national seismic network and the earthquake and tsunami monitoring and surveillance systems. Adv. Geosci. 43, 31-38. https://doi.org/10.5194/adgeo-43-31-2016.

Murphy, S., Di Toro, G., Romano, F., Scala, A., Lorito, S., Spagnuolo, E., Aretusini, S., Festa, G., Piatanesi, A., Nielsen, S., 2018. Tsunamigenic earthquake simulations using experimentally derived friction laws. Earth Planet. Sci. Lett. 486, 155-165. https://doi.org/10.1016/j.epsl.2018.01.011.

Oglesby, D.D., Archuleta, R.J., Nielsen, S.B., 1998. Earthquakes on dipping faults: the effects of broken symmetry. Science 280, 1055-1059. https://doi.org/10.1126/ science.280.5366.1055.

Ohnaka, M., Kuwahara, Y., Yamamoto, K., 1987. Constitutive relations between dynamic physical parameters near a tip of the propagating slip zone during stickslip shear failure. Tectonophysics 144, 109-125. https://doi.org/10.1016/00401951(87)90011-4.

Palgunadi, K.H., Gabriel, A.A., Ulrich, T., Lopez-Comino, J.A., Mai, P.M., 2020. Dynamic fault interaction during a fluid-injection-induced earthquake: the $2017 \mathrm{mw} 5.5$ pohang event. Bull. Seismol. Soc. Am. 110, 2328-2349. https://doi.org/10.1785/ 0120200106

Palmer, A.C., Rice, J.R., 1973. The growth of slip surfaces in the progressive failure of over-consolidated clay. Proc. R. Soc. Lond. Ser. A, Math. Phys. Sci. 332, 527-548. https://doi.org/10.1098/rspa.1973.0040.

Pelties, C., Gabriel, A.A., Ampuero, J.P., 2014. Verification of an ADER-DG method for complex dynamic rupture problems. Geosci. Model Dev. 7, 847-866. https:// doi.org/10.5194/gmd-7-847-2014.

Pizzi, A., Di Domenica, A., Gallovič, F., Luzi, L., Puglia, R., 2017. Fault segmentation as constraint to the occurrence of the main shocks of the 2016 central Italy seismic sequence. Tectonics 36, 2370-2387. https://doi.org/10.1002/2017TC004652.

Porreca, M., Minelli, G., Ercoli, M., Brobia, A., Mancinelli, P., Cruciani, F., Giorgetti, C., Carboni, F., Mirabella, F., Cavinato, G., Cannata, A., Pauselli, C., Barchi, M.R., 2018. Seismic reflection profiles and subsurface geology of the area interested by the 2016-2017 earthquake sequence (Central Italy). Tectonics 37, 1116-1137. https://doi.org/10.1002/2017TC004915.

Ragon, T., Sladen, A., Simons, M., 2018. Accounting for uncertain fault geometry in earthquake source inversions - I: theory and simplified application. Geophys. J. Int. 214, 1174-1190. https://doi.org/10.1093/gji/ggy187.

Ripperger, J., Ampuero, J.P., Mai, P.M., Giardini, D., 2007. Earthquake source characteristics from dynamic rupture with constrained stochastic fault stress. J. Geophys. Res., Solid Earth 112, 4311. https://doi.org/10.1029/2006JB004515.

Ruggieri, R., Scuderi, M.M., Trippetta, F., Tinti, E., Brignoli, M., Mantica, S., Petroselli, S., Osculati, L., Volontè, G., Collettini, C., 2021. The role of shale content and pore-water saturation on frictional properties of simulated carbonate faults. Tectonophysics 807, 228811. https://doi.org/10.1016/j.tecto.2021.228811.

Savran, W.H., Olsen, K.B., 2020. Kinematic rupture generator based on 3-D spontaneous rupture simulations along geometrically rough faults. J. Geophys. Res., Solid Earth 125, 1-22. https://doi.org/10.1029/2020JB019464.
Schmedes, J., Archuleta, R.J., Lavallée, D., 2010. Correlation of earthquake source parameters inferred from dynamic rupture simulations. J. Geophys. Res. 115, B03304. https://doi.org/10.1029/2009JB006689.

Scognamiglio, L., Tinti, E., Casarotti, E., Pucci, S., Villani, F., Cocco, M., Magnoni, F., Michelini, A., Dreger, D., 2018. Complex fault geometry and rupture dynamics of the Mw 6.5, 30 October 2016, central Italy earthquake. J. Geophys. Res., Solid Earth 123, 2943-2964. https://doi.org/10.1002/2018JB015603.

Scuderi, M.M., Niemeijer, A.R., Collettini, C., Marone, C., 2013. Frictional properties and slip stability of active faults within carbonate-evaporite sequences: the role of dolomite and anhydrite. Earth Planet. Sci. Lett. 369-370, 220-232. https:// doi.org/10.1016/j.epsl.2013.03.024.

Shimizu, K., Yagi, Y., Okuwaki, R., Fukahata, Y., 2020. Development of an inversion method to extract information on fault geometry from teleseismic data. Geophys. J. Int. 220, 1055-1065. https://doi.org/10.1093/gji/ggz496.

Spudich, P., Guatteri, M., Otsuki, K., Minagawa, J., 1998. Use of Fault striations and Dislocation Models to Infer Tectonic Shear Stress during the 1995 Hyogo-ken Nanbu (Kobe) Earthquake. Technical Report 2. http://pubs.geoscienceworld.org/ ssa/bssa/article-pdf/88/2/413/2709377/BSSA0880020413.pdf.

Tang, R., Yuan, J., Gan, L., 2021. Free-surface-induced supershear transition in 3-D simulations of spontaneous dynamic rupture on oblique faults. Geophys. Res. Lett. 48, e2020GL091621. https://doi.org/10.1029/2020GL091621.

Tinti, E., Cocco, M., Fukuyama, E., Piatanesi, A., 2009. Dependence of slip weakening distance (Dc) on final slip during dynamic rupture of earthquakes. Geophys. J. Int. 177, 1205-1220. https://doi.org/10.1111/j.1365-246X.2009.04143.x.

Tinti, E., Scognamiglio, L., Michelini, A., Cocco, M., 2016. Slip heterogeneity and directivity of the ML 6.0, 2016, Amatrice earthquake estimated with rapid finitefault inversion. Geophys. Res. Lett. 43. https://doi.org/10.1002/2016GL071263.

Tinti, E., Spudich, P., Cocco, M., 2005. Earthquake fracture energy inferred from kinematic rupture models on extended faults. J. Geophys. Res. 110, B12303. https:// doi.org/10.1029/2005JB003644.

Ulrich, T., Gabriel, A.A., Ampuero, J.P., Xu, W., 2019. Dynamic viability of the 2016 Mw 7.8 Kaikōura earthquake cascade on weak crustal faults. Nat. Commun. 10, 1-16. https://doi.org/10.1038/s41467-019-09125-w.

Uphoff, C., Rettenberger, S., Bader, M., Madden, E.H., Ulrich, T., Wollherr, S., Gabriel, A.A., 2017. Extreme scale multi-physics simulations of the tsunamigenic 2004 Sumatra megathrust earthquake. In: Proceedings of the International Conference for High Performance Computing, Networking, Storage and Analysis, SC 2017. Association for Computing Machinery, Inc., New York, NY, USA, pp. 1-16. https:// dl.acm.org/doi/10.1145/3126908.3126948.

Viesca, R.C., Garagash, D.I., 2015. Ubiquitous weakening of faults due to thermal pressurization. Nat. Geosci. 8, 875-879. https://doi.org/10.1038/ngeo2554.

Walters, R.J., Gregory, L.C., Wedmore, L.N.J., Craig, T.J., Mccaffrey, K., Wilkinson, M., Chen, J., Li, Z., Elliott, J.R., Goodall, H., Iezzi, F., Livio, F., Michetti, A.M., Roberts, G., Vittori, E., 2018. Dual control of fault intersections on stop-start rupture in the 2016 Central Italy seismic sequence. Earth Planet. Sci. Lett. 500, 1-14. https://doi.org/10.1016/j.epsl.2018.07.043.

Wang, K., Dreger, D.S., Tinti, E., Bürgmann, R., Taira, T., 2020. Rupture process of the 2019 ridgecrest, California mw 6.4 foreshock and mw 7.1 earthquake constrained by seismic and geodetic data. Bull. Seismol. Soc. Am. 110, 1603-1626. https:// doi.org/10.1785/0120200108.

Weng, H., Yang, H., 2018. Constraining frictional properties on fault by dynamic rupture simulations and near-field observations. J. Geophys. Res., Solid Earth 123, 6658-6670. https://doi.org/10.1029/2017JB015414.

Wollherr, S., Gabriel, A., Mai, P.M., 2019. Landers 1992 "reloaded": integrative dynamic earthquake rupture modeling. J. Geophys. Res., Solid Earth 124, 6666-6702. https://doi.org/10.1029/2018JB016355.

Wollherr, S., Gabriel, A.A., Uphoff, C., 2018. Off-fault plasticity in three-dimensional dynamic rupture simulations using a modal discontinuous Galerkin method on unstructured meshes: implementation, verification and application. Geophys. J. Int. 214, 1556-1584. https://doi.org/10.1093/GJI/GGY213.

Yagi, Y., Fukahata, Y., 2011. Introduction of uncertainty of Green's function into waveform inversion for seismic source processes. Geophys. J. Int. 186, 711-720. https://doi.org/10.1111/j.1365-246X.2011.05043.x. 